\title{
Brain natriuretic peptide is able to stimulate cardiac progenitor cell proliferation and differentiation in murine hearts after birth
}

\author{
Christelle Bielmann $\cdot$ Stéphanie Rignault-Clerc $\cdot$ Lucas Liaudet $\cdot$ \\ Feng Li · Tetsuo Kunieda - Chizuru Sogawa - Tamara Zehnder • \\ Bernard Waeber · François Feihl • Nathalie Rosenblatt-Velin
}

Received: 13 October 2014/Revised: 6 November 2014/ Accepted: 19 November 2014/Published online: 2 December 2014

(C) Springer-Verlag Berlin Heidelberg 2014

\begin{abstract}
Brain natriuretic peptide (BNP) contributes to heart formation during embryogenesis. After birth, despite a high number of studies aimed at understanding by which mechanism(s) BNP reduces myocardial ischemic injury in animal models, the actual role of this peptide in the heart remains elusive. In this study, we asked whether BNP treatment could modulate the proliferation of endogenous cardiac progenitor cells (CPCs) and/or their differentiation into cardiomyocytes. CPCs expressed the NPR-A and NPR-B receptors in neonatal and adult hearts, suggesting
\end{abstract}

C. Bielmann and S. Rignault-Clerc contributed equally to this work.

Electronic supplementary material The online version of this article (doi:10.1007/s00395-014-0455-4) contains supplementary material, which is available to authorized users.

C. Bielmann - S. Rignault-Clerc - T. Zehnder · B. Waeber ·

F. Feihl $\cdot$ N. Rosenblatt-Velin $(\varangle)$

Division de Physiopathologie Clinique, Centre Hospitalier

Universitaire Vaudois and University of Lausanne, Bugnon 7a,

1005 Lausanne, Switzerland

e-mail: nathalie.rosenblatt@chuv.ch

L. Liaudet

Service de Médecine Intensive Adulte, Centre Hospitalier Universitaire Vaudois and University of Lausanne, Lausanne, Switzerland

F. Li

Department of Pathology and Laboratory Medecine, University of North Carolina, Chapel Hill, Wilmington, NC, USA

T. Kunieda

Graduate School of Environmental and Life Science, Okayama

University, Okayama, Japan

C. Sogawa

Graduate School of Natural Science and Technology, Okayama

University, Okayama, Japan their ability to respond to BNP stimulation. BNP injection into neonatal and adult unmanipulated mice increased the number of newly formed cardiomyocytes (neonatal: $+23 \%, p=0.009$ and adult: $+68 \%, p=0.0005)$ and the number of proliferating CPCs (neonatal: $+142 \%$, $p=0.002$ and adult: $+134 \%, p=0.04)$. In vitro, BNP stimulated CPC proliferation via NPR-A and CPC differentiation into cardiomyocytes via NPR-B. Finally, as BNP might be used as a therapeutic agent, we injected BNP into mice undergoing myocardial infarction. In pathological conditions, BNP treatment was cardioprotective by increasing heart contractility and reducing cardiac remodelling. At the cellular level, BNP stimulates CPC proliferation in the non-infarcted area of the infarcted hearts. In the infarcted area, BNP modulates the fate of the endogenous CPCs but also of the infiltrating $\mathrm{CD} 45^{+}$cells. These results support for the first time a key role for BNP in controlling the progenitor cell proliferation and differentiation after birth. The administration of BNP might, therefore, be a useful component of therapeutic approaches aimed at inducing heart regeneration.

Keywords Brain natriuretic peptide - Cardiac progenitor cells - Heart regeneration - Cardiomyocytes .

Differentiation · Proliferation $\cdot$ Natriuretic peptide receptor
Abbreviations
BNP Brain natriuretic peptide
BrdU 5-Bromo-2'-deoxyuridine
CPCs Cardiac progenitor cells
GFP Green fluorescent protein
NMCs Non-myocyte cells
NPR-A Natriuretic peptide receptor A
NPR-B Natriuretic peptide receptor B 


\section{Introduction}

Brain natriuretic peptide (BNP) is a cardiac hormone, secreted mainly by ventricular cardiomyocytes. BNP binding to two guanylyl cyclase receptors denoted NPR-A and NPR-B, leads to the generation of intracellular cGMP. The accumulation of cGMP in the cytoplasm activates the protein kinase $\mathrm{G}(\mathrm{PKG})$ and the phosphodiesterases 2, 3 or 5 [33].

Brain natriuretic peptide was shown to induce cardioprotection in animal models of heart failure [7, 10, 14, 18, 34, 45]. In human hearts, although BNP is immediately secreted in the blood in large amounts after heart injury, a large part of it is in a form devoid of biological activity [11], suggesting that pharmacological treatment using recombinant BNP could be beneficial for patients developing acute heart failure. The first clinical trials using nesiritide (recombinant human BNP) highlighted positive hemodynamic and clinical effects but also severe adverse effects, such as hypotension, renal failure and higher mortality rate in the group of BNP-treated patients [3]. Recently, new clinical studies demonstrated that low doses of Nesiritide administered to patients with acute heart failure could improve cardiac function without inducing hypotension, nephrotoxicity or increase in the rate of death or rehospitalization $[3,12,13,20,26,31,38]$. Furthermore, treatment of patients suffering from heart failure with an inhibitor of the receptor for Neprilysin, an endopeptidase able to degrade natriuretic peptides, reduced the risks of death and of hospitalisation when compared to patients treated with enalapril [28]. Altogether, these new results reopened the debate about the usefulness of BNP therapy for patients with heart failure [21].

The present uncertainty concerning the usefulness of BNP therapy for patients with heart failure may in part reflect the lack of knowledge about the mechanisms by which BNP acts on cardiac cells. Nevertheless, its cardiac protective role in animals was attributed to fibrosis inhibition, to KATP channel opening, as well as to reduction of cardiomyocyte apoptosis and hypertrophy [14, 19, 29, 40, 43, 45]. Interestingly, Abdelalim and his group highlighted an unexpected role of BNP in murine embryonic stem cells (ES), which surprisingly secrete BNP and also express both of its receptors, NPR-A and NPR-B [1,2]. They demonstrated that BNP controls ES cell fate depending on the receptor to which it binds [1, 2]. Another member of the natriuretic peptide family, the atrial natriuretic peptide, seems also to be able to activate or repress cardiomyocyte proliferation during embryogenesis in zebrafish and this, in a concentration-dependent manner [5]. These results are in line with several studies suggesting that BNP in the developing embryo does not only contribute to the homeostasis of salt, water and blood pressure, but also has a role in controlling the differentiation of embryonic cells into cardiomyocytes [9, 40]. Whether this effect of BNP continues after birth, is unknown.

We investigated in this report the effect of BNP treatment in physiological (i.e. on neonatal and adult "healthy" murine hearts) and in pathophysiological (i.e. in infarcted murine hearts) conditions. We demonstrate here for the first time that cardiac progenitor cells (CPCs) are able to respond to BNP stimulation in a neonatal and even in an adult mouse heart. In vivo, BNP injections lead to increased CPC proliferation and increased number of $\mathrm{Nkx} 2.5^{+}$cardiomyocytes. In vitro experiments show that BNP can directly act on CPCs via NPR-A to stimulate their proliferation and via NPR-B to induce their differentiation into cardiomyocytes. Finally, in pathological conditions in vivo, BNP is able to increase the number of $\mathrm{Nkx} 2.5^{+}$cells in both the infarcted and noninfarcted areas of BNP-treated infarcted hearts 1 week after surgery.

These results highlight a new role for BNP in the heart after birth. BNP has thus, to be considered as an essential factor able to induce cardiac cell regeneration following cardiac injury.

\section{Materials and methods}

\section{Mice}

All the experiments were approved by the Swiss animal welfare authorities (Veterinary Office of Lausanne, Switzerland). Neonatal C57BL/6 pups (3-4 days) and adult male C57BL/6 (age 10 and 18 weeks) were purchased from Janvier (Le Genest-Saint-Isle, France) and were housed in the animal facility until use for experiments. Myh6MerCreMer mice (JAK-5657) and Tomato-EGFP mice (JAK-7576) were purchased from The Jackson Laboratory. Heterozygous MerCreMer/Tomato-EGFP mice were used in this study at the age of 3 or 10 weeks. NPR-A $(-/-)$ (NPR-A KO) and NPR-B deficient (C57BL/6 J-Npr $2^{s l w}$ ) pups (1-2 days) were used in this study. NPR-B deficient mice do not survive more than 3 days.

In vivo experimental design

Neonatal (3-4 days old) and adult (10 weeks old) C57BL/6 mice were injected intraperitoneally (ip) with BNP $(1 \mu \mathrm{g} /$ mouse in the neonatal mice and $2 \mu \mathrm{g}$ /mouse in the adult mice) (recombinant mouse C 1-45 peptide; American Peptide Co, Sunnyvale, CA, US) or $\mathrm{NaCl}$. Three injections were carried out weekly during 2 weeks. These doses of BNP had been shown to be effective on mobilisation, 
proliferation and differentiation of endothelial precursor cells in BNP-injected mice [23, 41].

Neonatal and adult mice had the same time of BNP exposure. Neonatal mice were sacrificed 3 days after the end of BNP injections, whereas adult mice were sacrificed 3 weeks after the end of injections to assess for the sustainability of BNP effect. Blood pressure was measured with the non-invasive tail cuff method, every 2 days during the 5 weeks of experiment in adult mice. The mice were trained 1 week before the onset of measurement.

Myocardial infarction was induced in 10-week-old C57 BL/6 mice by ligation of the left anterior descending coronary artery (LAD). Briefly, mice were anaesthetised (ketamine $(65 \mathrm{mg} / \mathrm{kg}) / x y l a z i n e ~(15 \mathrm{mg} / \mathrm{kg})$, acépromazine $(2 \mathrm{mg} / \mathrm{kg}))$, intubated and ventilated. The chest cavity was entered through the third intercostal space at the left upper sternal border, and myocardial infarction was induced by ligature of the LAD with a 7-0 nylon suture at about $1-2 \mathrm{~mm}$ from the atria. Shamoperated mice underwent the same operation but without tightening the knot. Directly after the surgery, $\mathrm{NaCl}$ or BNP $(1 \mu \mathrm{g} / 20 \mathrm{~g}$ in $20 \mu \mathrm{l})$ was injected into the myocardium. Thereafter, BNP ( $2 \mu \mathrm{g} /$ mouse) was injected ip every 2 days. Echocardiographies were performed at baseline (i.e. before surgical procedure) or 1 or 4 weeks after surgery.

Mice were sacrificed 10 days or 4 weeks after infarct induction and hearts were removed. The infarction zone (Infarction zone) was separated from rest of the heart (Noninfarcted zone).

\section{Echocardiography and measurements}

Transthoracic echocardiographies were performed on adult unmanipulated or infarcted mice using a $30 \mathrm{M}-\mathrm{Hz}$ probe and the Vevo 770 Ultrasound machine (VisualSonics, Toronto, Ontario, Canada) as described [37]. All measurements were done from leading edge to leading edge according to the American Society of Echocardiography guidelines.

Briefly, cardiac parameters, including diastolic and systolic-free wall thickness, internal diastolic and systolic left ventricular diameter, as well as ejection fraction (EF) and fractional shortening, were evaluated on lightly anaesthetised mice ( $1 \%$ isoflurane). We computed EF as an index of contractility. However, EF is depending on preloading conditions. Since we noted that after myocardial infarction, the preloading conditions were different between the BNP-treated and untreated mice, we calculated the ratio of EF on LV Vol;d (EF@LV Vol;d) as a new index of contractility, taking into account of these differences of preload. Such correction is indeed in agreement with comparable approaches used in volumetric technology to assess cardiac function [25]. Furthermore, according to the fact that changes in left ventricle volume can be considered as an index of remodeling [22], we calculated the percentage of increase of the left ventricle volume 1 and 4 weeks after surgery, which is the ratio between (LV Vol;d 1 or 4 weeks - LV Vol;d before surgery) and LV Vol;d before surgery $\times 100$.

\section{Cell culture}

Neonatal cardiac cells were isolated as previously described [36] and cultured in specific media favouring cell proliferation (medium $\mathrm{P}$ ) for up to 11 days or cell differentiation (medium C) for up to 3 weeks. Cells were treated or not with $1 \mu \mathrm{M}$ murine BNP (recombinant mouse C 1-45 peptide; American Peptide Co, Sunnyvale, CA). A dose response of BNP on NMCs was performed in both media (medium $\mathrm{P}$ and $\mathrm{C}$ ) to choose the optimal BNP concentration able to modulate CPC's fate. According to our results, the following experiments will be done using $1 \mu \mathrm{M}$ BNP in vitro (Supplemental Fig. 4).

\section{BrdU incorporation in vivo}

$18 \mathrm{~h}$ before sacrifice, $40 \mu \mathrm{l} \mathrm{BrdU}(10 \mathrm{mg} / \mathrm{ml})$ was injected ip into neonatal mice treated or not with BNP for 2 weeks to assess for cell proliferation. For adult healthy or infarcted animals, BrdU (1 mg/ml) was added to drinking water $48 \mathrm{~h}$ before sacrifice. In adult animals, to assess for cardiomyocyte proliferation, BrdU ( $1 \mathrm{mg} / \mathrm{ml})$ was added to drinking water 9 days before sacrifice as previously described [6].

Statistical analysis

All results were presented as mean \pm SEM. Statistical analyses were performed using the unpaired Student $T$ test or the Wilcoxon test. The alpha level of all tests was 0.05 .

A more complete description of the methods is included in the supplementary methods file.

\section{Results}

In a preliminary step, we demonstrated that BNP and its receptors are expressed more abundantly in neonatal compared to adult mouse hearts, suggesting an involvement of BNP pathways in heart physiological growth (Supplemental Fig. 1 and data 1). We determined also that cardiomyocytes and non-myocyte (NMCs) cardiac cells express BNP receptors in neonatal and adult hearts (Supplemental Fig. 2). Among NMCs, we clearly established 
that $\mathrm{Nkx} 2.5^{+}$cells, which are not cardiomyocytes, expressed NPR-A and/or NPR-B receptors (Fig. 1).

BNP injections to neonatal mice lead to increased number of CPCs and newly formed cardiomyocytes

To determine whether BNP administration was able to modulate CPC's fate in vivo, BNP or saline was injected intraperitoneally 3 times per week for 2 weeks into C57BL/6 neonatal mice, starting at an age of 3-4 days. At sacrifice, 3 days after the last injection, no difference in the body weight, heart weight or their ratio was apparent between the BNP injected and the control mice (data not shown). The number of cardiomyocytes and NMCs were compared between BNP- and saline-injected neonatal mice after enzymatic digestion of the hearts (Fig. 2a). Higher numbers of cardiomyocytes $(+34 \%, p=0.003)$ were detected in BNP-treated hearts. The higher Troponin I level (Fig. 2c) and the reduced cross-sectional area
$(-14 \%, p<0.0001)$ (Fig. 2b) of the cardiomyocytes in BNP-treated hearts corroborated the fact that more cardiomyocytes were present after BNP treatment in neonatal hearts. Staining for laminin and Nkx2.5 was also used as above to discriminate between newly formed cardiomyocytes (large cells positive for $\mathrm{Nkx} 2.5$, white arrows on Fig. 2d), mature cardiomyocytes (large cells negative for $\mathrm{Nkx} 2.5$ ), NMCs (small cells negative for Nkx2.5) and CPCs (small cells positive for Nkx2.5, yellow arrows on Fig. 2d). BNP treatment increased the number of newly formed cardiomyocytes (in control mice $173 \pm 10 \mathrm{Nkx}_{2} .5^{+}$cardiomyocytes $/ 0.16 \mathrm{~mm}^{2}$ versus $212 \pm 6$ in BNP-injected mice; $p=0.009$ ) and CPCs (in control mice $10 \pm 1.5 \mathrm{CPCs} / 0.16 \mathrm{~mm}^{2}$ versus $25 \pm 3$ in BNP-treated mice; $p=0.002$ ) (Fig. 2d, e). In correlation with the higher number of CPCs found in the neonatal hearts of BNP-injected mice, was the increase of mRNAs coding for Nanog, Nkx2.5, Gata-4 and Sca-1 but not c-kit (Supplemental Fig. 3).
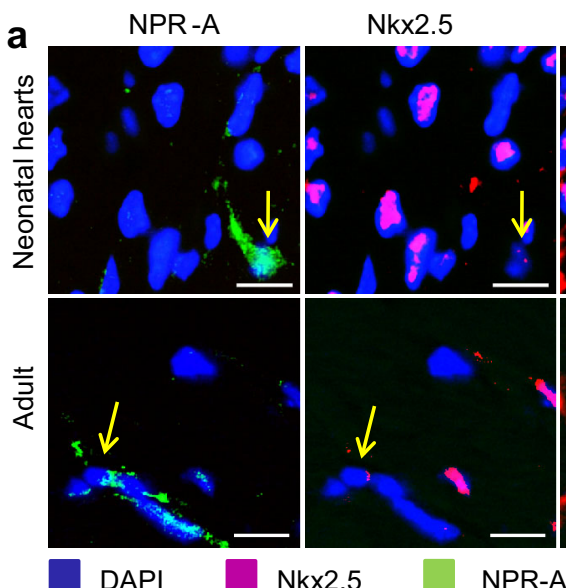

Merge /laminin
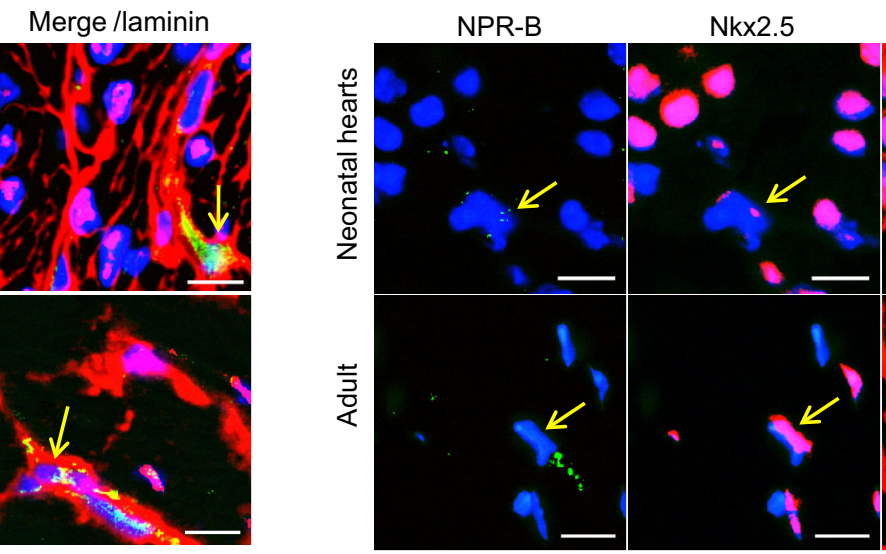

Merge/laminin

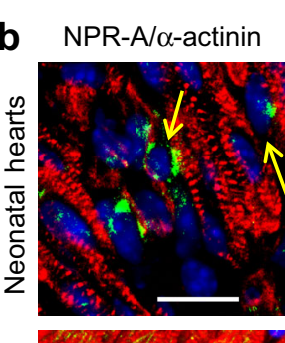

$\mathrm{Nkx2.5/ \alpha -actinin}$

laminin
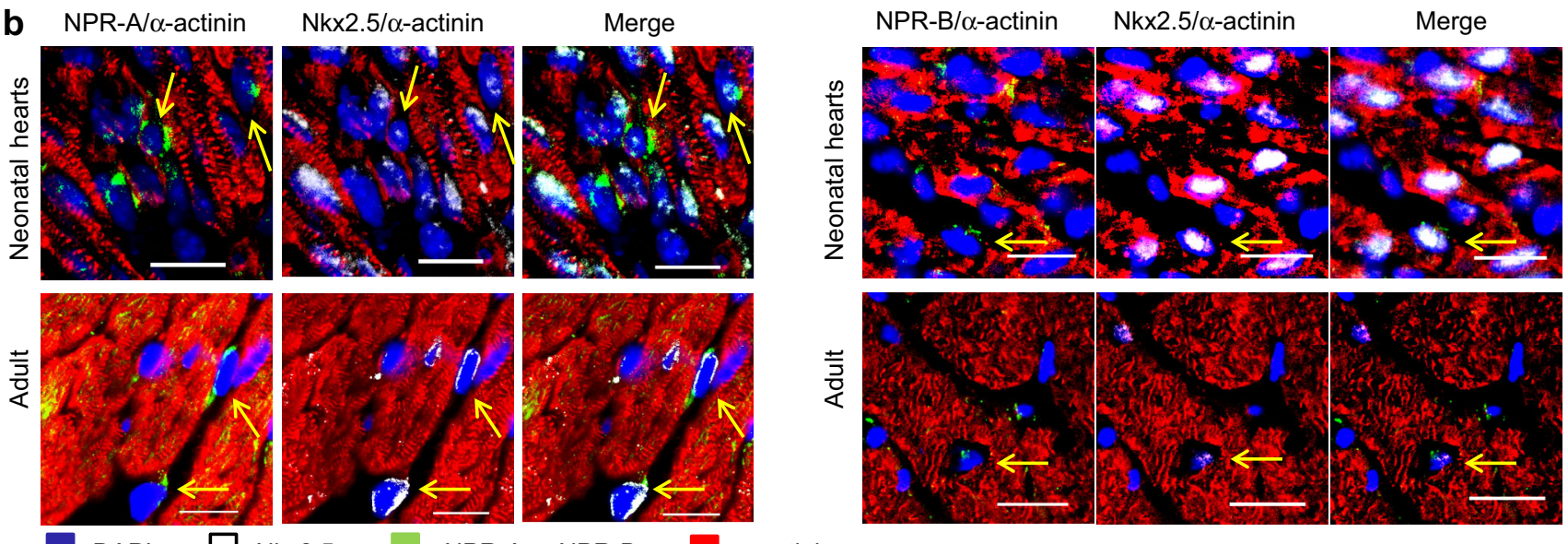

DAPI

$\mathrm{Nkx} 2.5$

NPR-A or NPR-B

$\alpha$-actinin

Fig. 1 Cardiac precursor cells express NPR-A and/or NPR-B receptors in neonatal and adult murine hearts. Representative pictures of immunostainings of neonatal or adult hearts. Scale bars represented
$10 \mu \mathrm{m}$. The yellow arrows point to CPCs expressing NPR-A or NPR$\mathrm{B}$, where CPCs are identified as being small $\mathrm{Nkx} 2.5^{+}$laminin $^{+}$cells (a) or $\mathrm{Nkx} 2.5^{+} \alpha$-actinin ${ }^{-}$cells (b) 


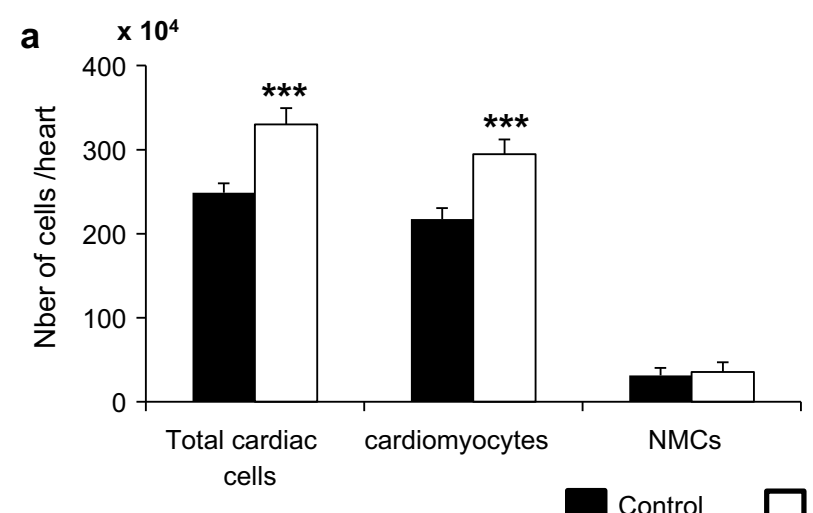

b

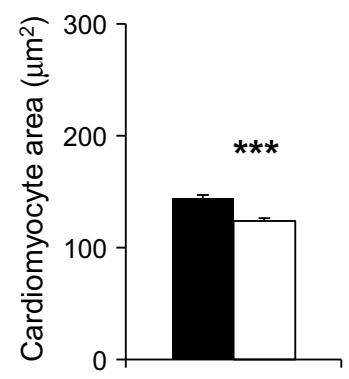

c
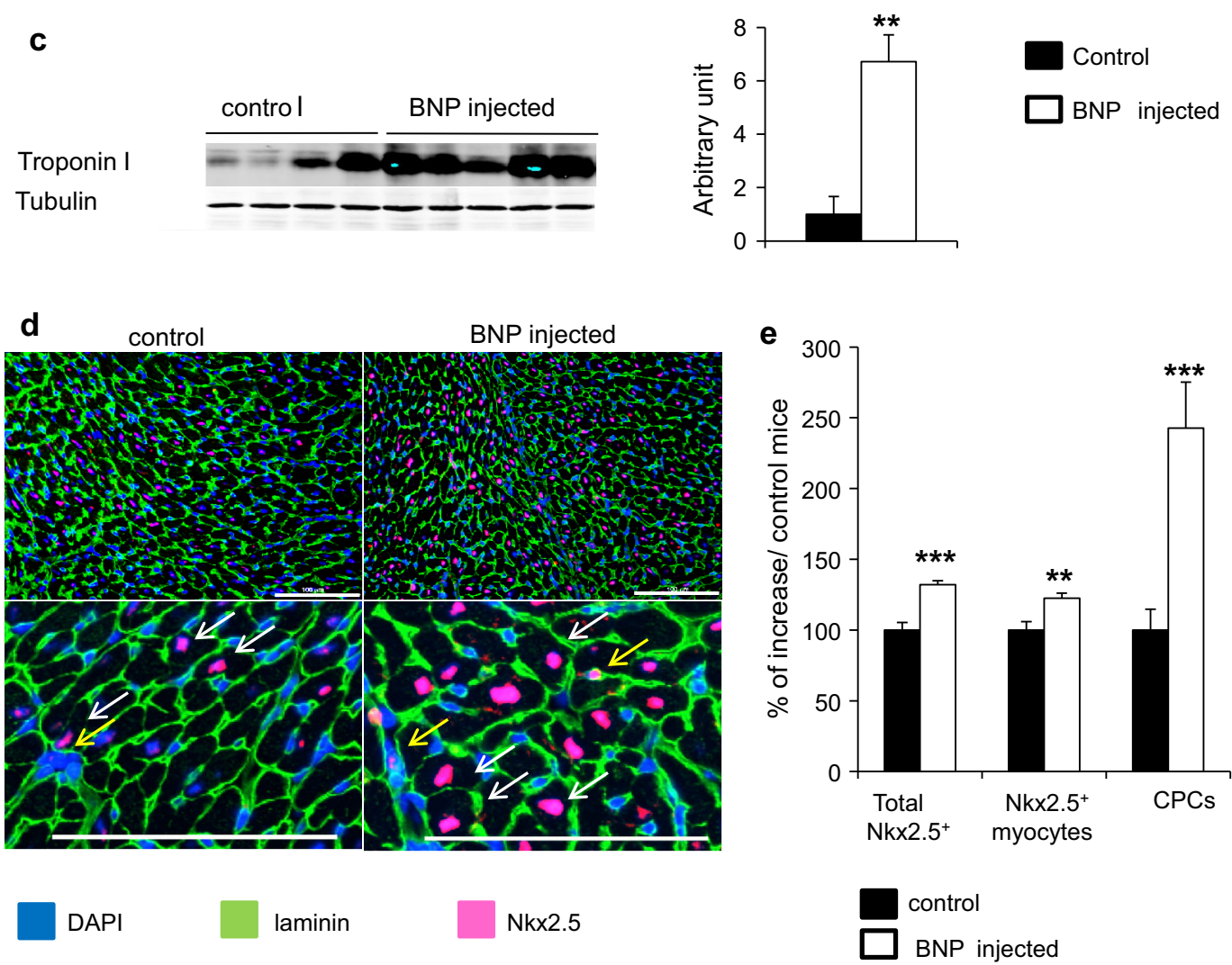

Fig. 2 Higher numbers of newly formed cardiomyocytes and CPCs in the heart of 3-week-old BNP-injected mice compared to salineinjected mice. a Neonatal mice (3 days old) were treated or not with BNP for 2 weeks. Mice were sacrificed 3 days after the last injection and the hearts were removed and digested to isolate and count all of the cardiac cells, the cardiomyocytes and the non-myocyte cells (NMCs). $n=6$ mice per group. b The area of cardiomyocytes (without discriminating between $\mathrm{Nkx} 2.5^{+}$or $\mathrm{Nkx} 2.5^{-}$cardiomyocytes) was measured in the hearts of control or BNP-injected mice. Data were obtained from at least 4-6 different pictures per mouse, $n=4$ mice per group. Each picture covered an area of $0.16 \mathrm{~mm}^{2} .600$ cardiomyocytes were measured in each group. c Western blot of

BNP stimulates the proliferation of cardiac progenitor cells in neonatal hearts

The mechanism by which BNP treatment led to increased number of CPCs was investigated. Neonatal mice were

Troponin I protein expression and quantification relative to tubulin in hearts from control or BNP-injected mice. d Representative pictures of hearts from control or BNP-injected mice stained for laminin (green), the nuclear transcription factor Nkx2.5 (pink) and DAPI (blue). Scale bars represent $100 \mu \mathrm{m}$. White arrows: newly formed cardiomyocytes. Yellow arrows: CPCs. e Total number of Nkx $2.5^{+}$ cells, of newly formed cardiomyocytes and of CPCs counted on heart sections from control or BNP-injected mice. Data were obtained from at least 6 different pictures per mouse, $n=6$ mice per group. Each picture covered an area of $0.16 \mathrm{~mm}^{2}$. Results expressed as fold increase above the numbers in control hearts. All data are mean \pm SEM, $* p<0.05 ; * * p<0.01 ; * * * p<0.005$

injected with BNP during 10 days and, $18 \mathrm{~h}$ before sacrifice, with BrdU to determine whether BNP stimulated CPC proliferation (Fig. 3). We used immunostainings against BrdU, laminin and $\mathrm{Nkx} 2.5$ to detect: (a) proliferating cardiomyocytes or newly differentiated cardiomyocytes 
originating from CPCs which were proliferating at the time of BrdU injection (large $\mathrm{Nkx}_{2.5^{+}} \mathrm{BrdU}^{+}$cells, white arrows in Fig. 3b), (b) proliferating NMCs (small Nkx2.5 $\mathrm{BrdU}^{+}$cells, green arrows in Fig. 3b) and (c) CPCs (small Nkx2.5 ${ }^{+}$BrdU $^{+}$cells, yellow arrows on Fig. 3b). BNP induced cell proliferation in vivo, as assessed by higher number of $\mathrm{BrdU}^{+}$cells in the hearts of BNP injected versus control mice (control: $102 \pm 4 \mathrm{BrdU}^{+}$cells $/ 0.16 \mathrm{~mm}^{2}$ versus $121 \pm 7$ cells in BNP-treated hearts; $p=0.03$ ). This effect concerned specifically the CPCs whose proliferation was particularly increased (control: $27 \pm 2 \mathrm{CPCs} /$ $0.16 \mathrm{~mm}^{2}$ versus $36 \pm 1$ in BNP-treated mice, $p=0.004$ ). The number of proliferating cardiomyocytes was slightly increased after BNP treatment $(+18 \%)$, an effect that did not reach significance $(p=0.12)$, suggesting that in our conditions BNP did not directly stimulate cardiomyocyte proliferation. BNP treatment did not affect the proliferation of other NMCs.

\section{BNP stimulates CPC proliferation via NPR-A in vitro}

In vitro experiments were performed to assess whether BNP is directly able to stimulate CPC proliferation. NMCs were isolated from neonatal mouse hearts and cultured up to 11 days with or without BNP in a medium favouring cell proliferation and inhibiting cell differentiation (i.e. medium $\mathrm{P})$. Among NMCs, $\mathrm{Nkx} 2.5^{+}$cells were identified as CPCs [36]. To determine which BNP concentration has to be used in vitro to modulate CPC's fate, several BNP concentrations were tested for their ability to increase or decrease mRNA expression of CPC-specific genes, such as Nkx2.5, c-kit and Sca-1 (Supplemental Fig. 4A). All following experiments in vitro were performed using $1 \mu \mathrm{M}$ BNP.

Immunostainings using antibodies against the proliferating cellular nuclear antigen (PCNA) and the nuclear transcription factor $\mathrm{Nkx} 2.5$ were performed (Fig. 4a) to evaluate the percentage of proliferating CPCs in the presence or absence of BNP. BNP specifically stimulated the proliferation of the CPCs $\left(+91 \%\right.$ of $\mathrm{Nkx}_{2.5}{ }^{+} \mathrm{PCNA}^{+}$cells in BNP-treated cells in comparison with untreated cells 4 days after the onset of treatment, $p=0.005$ ) (Fig. 4b). Consequently, increased percentages of $\mathrm{Nkx} 2.5^{+}$cells were detected in BNP-treated NMCs $4(+71 \%$, $p=0.004)$ and 11 days $(+58 \%, p<0.00001)$ after the onset of BNP treatment (Fig. 4b). Accordingly to these results, were the increased Nkx2.5 mRNA levels (Fig. 4c).

As CPCs expressed both BNP receptors (see Fig. 1), we investigated via which receptor BNP stimulates $\mathrm{CPC}$ proliferation. NPR-A KO and NPR-B deficient NMCs were isolated from neonatal hearts and cultured in the same conditions as previously described for wild-type mice. In absence of NPR-A, BNP no longer stimulated CPC proliferation as shown in Fig. 4d. Interestingly, the percentage of $\mathrm{Nkx} 2.5^{+}$cells in the NPR-A KO NMC culture, even in the absence of BNP, was higher than in cell culture of wild-type cells after 11 days $(60.1 \pm 4.7 \%$ in NPR-A $\mathrm{KO}$ cells versus $24.6 \pm 3.2 \%$ in wild-type cells, $p<0.0001$ ), suggesting that in the absence of NPR-A, CPCs proliferated extensively. NPR-A appears also as a regulator of $\mathrm{CPC}$ proliferation in vitro.

$\mathrm{Nkx} 2.5^{+} \mathrm{NMCs}$ deficient for the expression of NPR-B proliferated, as did wild-type cells, in the presence of BNP (Fig. 4e).

BNP injections to adult mice also lead to increased number of CPCs and newly formed cardiomyocytes

In C57BL/6 adult mice, BNP or saline was injected intravenously 3 times per week for 2 weeks, starting at an age of 10 weeks. To assess for the sustainability of BNP effect, we sacrificed the mice 3 weeks after the last injection. No difference in systolic blood pressure (measured daily during the BNP treatment) was detected between BNP treated and saline-treated mice (Supplemental Table 2). Cardiac parameters and structure were measured by echocardiography (Supplemental Table 2) and were not different between both groups. In particular, heart rate, cardiac output, left ventricular diastolic volume (LV Vol;d) as well as the index of systemic vascular resistance were similar between BNP and saline-injected mice. These results suggest that BNP treatment (at the dose used in this study) had no significant effect on volumia and no peripheral vascular effect.

At sacrifice, the heart weight and its ratio to body weight were significantly reduced (respectively, of -11 and $-7 \%, p<0.05)$ in BNP-injected mice compared to controls (Fig. 5a). The mRNA expression of genes coding for Nkx2.5, Mlc2v, Sca-1, Troponin T, ANF, $\alpha$ SMA, as well as the $\alpha / \beta$ MHC ratio did not differ between BNP injected and control animals, suggesting that BNP injections induced no hypertrophy in adult hearts (data not shown).

However, BNP treatment increased the total number of $\mathrm{Nkx} 2.5^{+}$cells in the heart (control: $74.5 \pm 6 \mathrm{Nkx} 2.5^{+}$ cells $/ 0.16 \mathrm{~mm}^{2}$ versus $131 \pm 1$ cells in BNP-treated hearts, $p=0.0001$ ) (Fig. 5b, c) and this effect concerned both the newly formed cardiomyocytes (i.e. cardiomyocytes expressing Nkx2.5) (control: $66 \pm 6 \mathrm{Nkx} 2.5^{+}$cardiomyo-

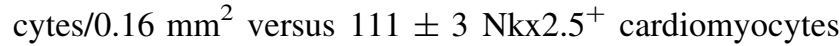
in BNP-treated mice; $p=0.005$ ) and the CPCs (control: $10 \pm 2 \mathrm{CPCs} / 0.16 \mathrm{~mm}^{2}$ versus $25 \pm 3 \mathrm{CPCs}$ in BNPtreated hearts; $p=0.04)$. Consistent with these observations, the cardiomyocytes of BNP-injected mice had a reduced cross-sectional area $(-6 \%, p=0.008)$ (Fig. $5 \mathrm{~d})$, and the BNP-treated hearts tended to express higher levels of the Troponin I protein (Fig. 5e). 
a

\section{몽}
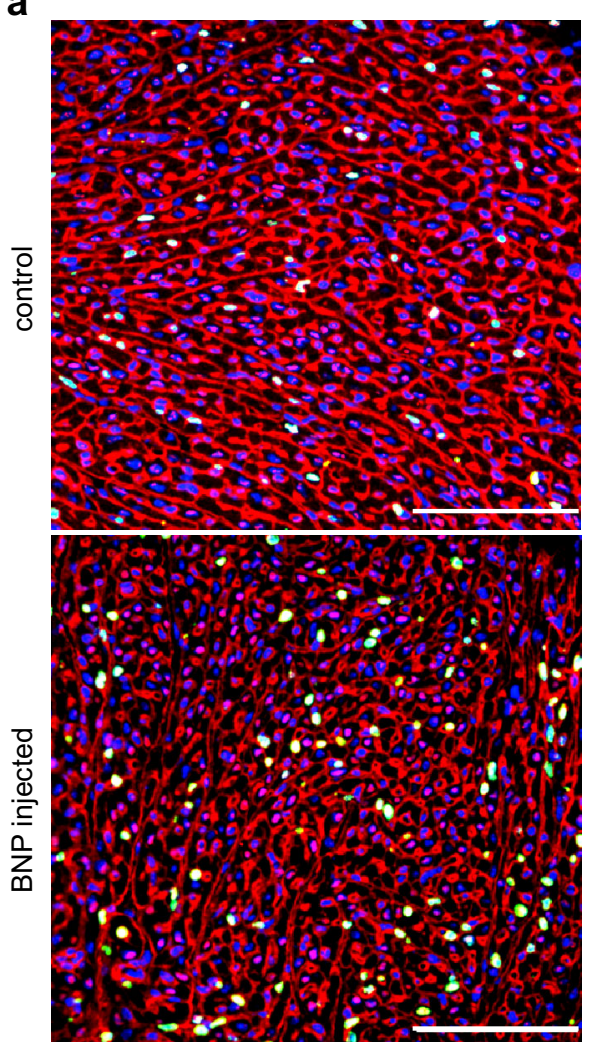

DAPI laminin

BrdU

C

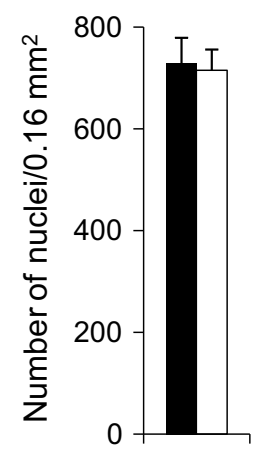

b
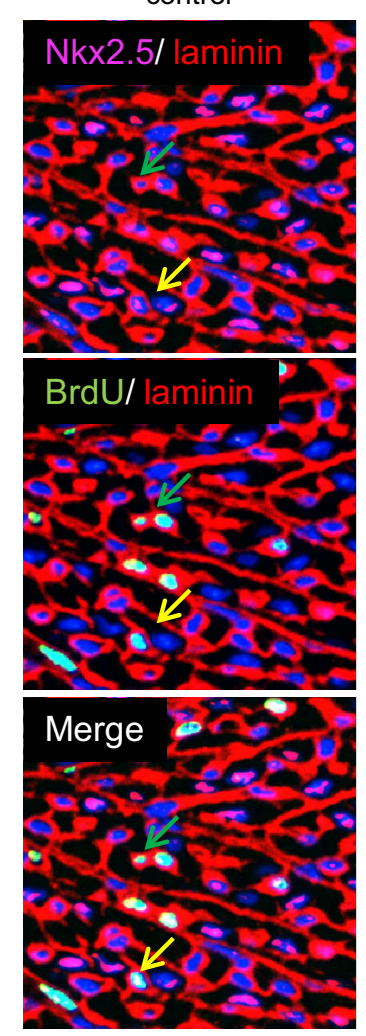

Nkx2.5
BNP injected
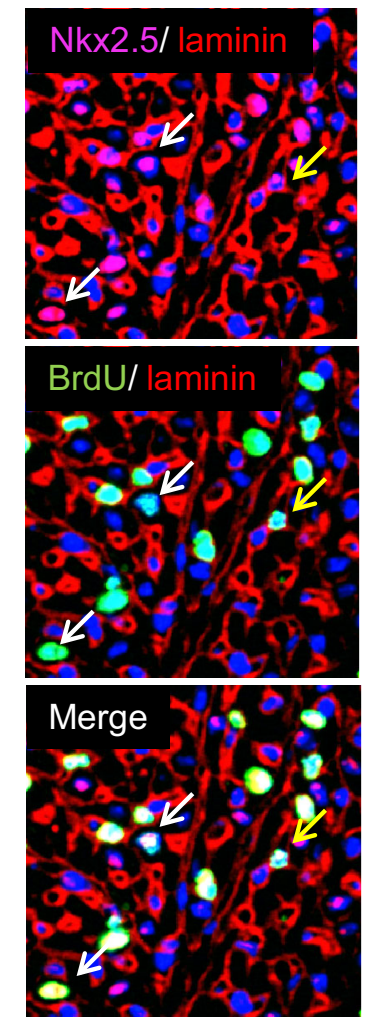

.

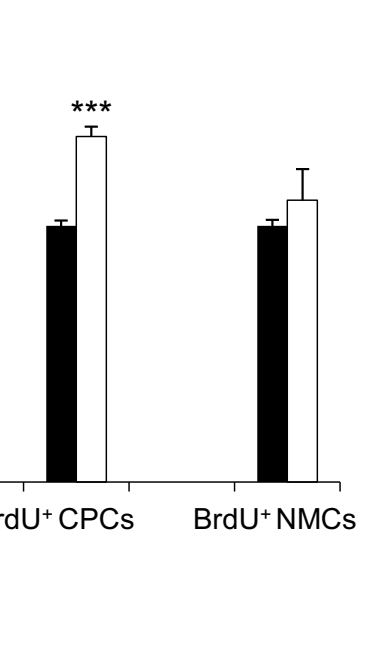

Control

BNP injected

Fig. 3 BNP injected to neonatal mice stimulates the proliferation of CPCs. a Heart sections from control or BNP-injected neonatal mice stained with antibodies against $\mathrm{BrdU}$ (green), laminin (red), $\mathrm{Nkx} 2.5$ (pink, in nucleus) and DAPI (blue). The mice were injected $18 \mathrm{~h}$ before sacrifice with BrdU. Scale bars represent $100 \mu \mathrm{m}$. b High magnification pictures of heart sections from control or BNP-injected mice stained for $\mathrm{Nkx} 2.5$ (pink), laminin (red), BrdU (green) and DAPI (blue). The width of each picture corresponds to $100 \mu \mathrm{m}$. White arrows: $\mathrm{BrdU}^{+}$newly formed cardiomyocytes, yellow arrows: $\mathrm{BrdU}^{+}$ CPCs, green arrows: $\mathrm{BrdU}^{+} \mathrm{NMCs}$. c Quantification of the total number of nuclei and of $\mathrm{BrdU}^{+}$cells in the hearts of control or BNPinjected mice. The numbers of positive cells were counted on at least six different pictures per mouse, $n=5$ mice Results expressed as fold increase above the numbers in control hearts. All data are mean \pm SEM, $* p<0.05 ; * * * p<0.005$. The colour of the arrows refers to panel B 


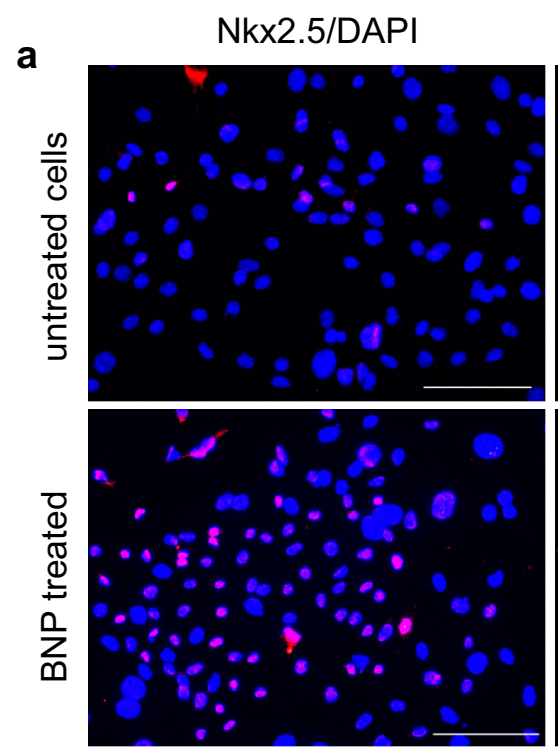

b
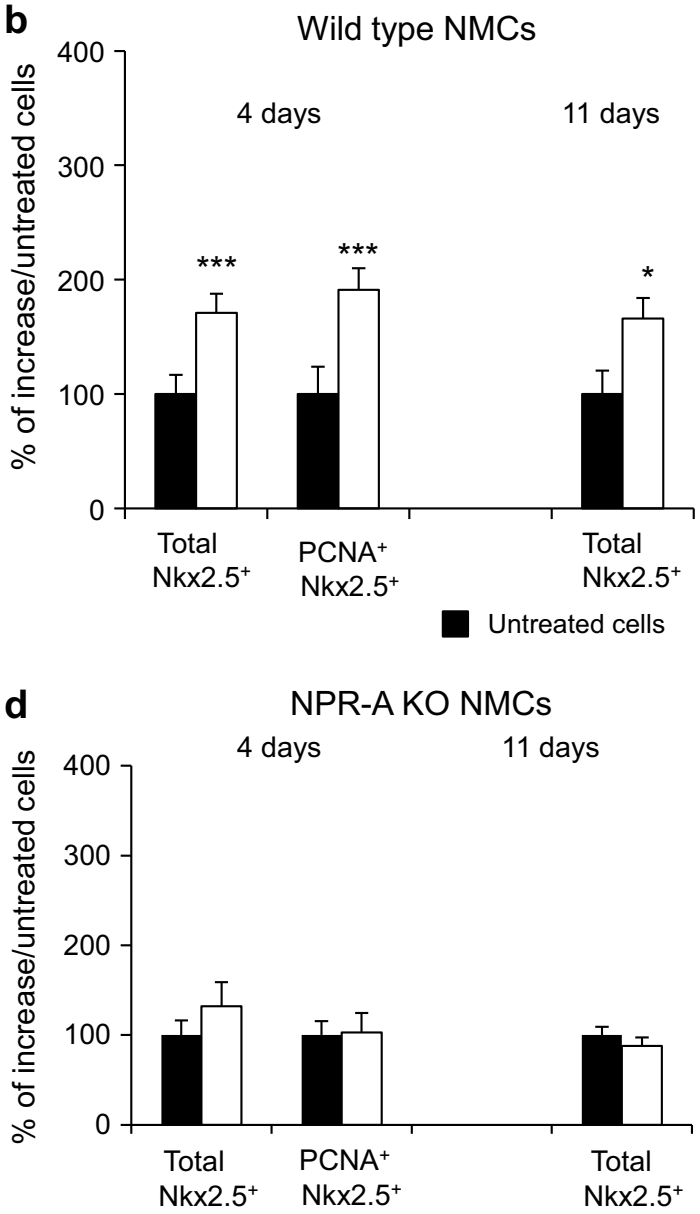

BNP induces the differentiation of CPCs

into cardiomyocytes in vivo

In the adult hearts of BNP-treated mice, the higher number of cardiomyocytes expressing $\mathrm{Nkx} 2.5$ could be
PCNA
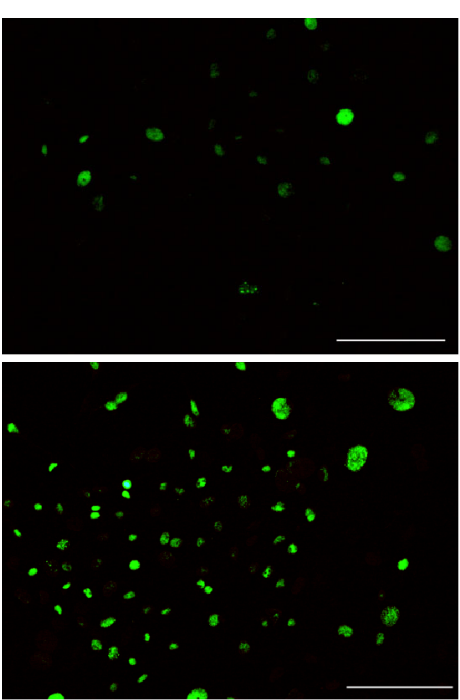

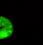

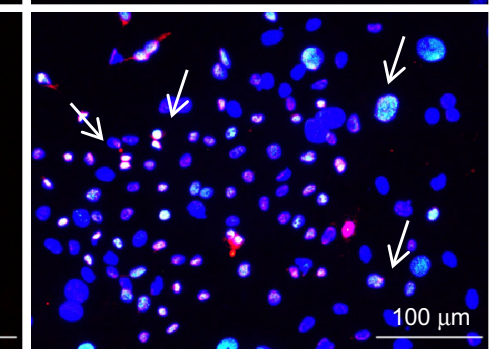

C

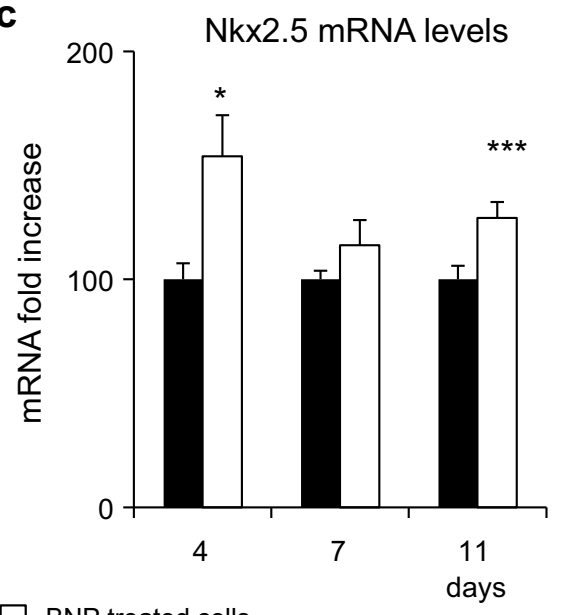

BNP treated cells

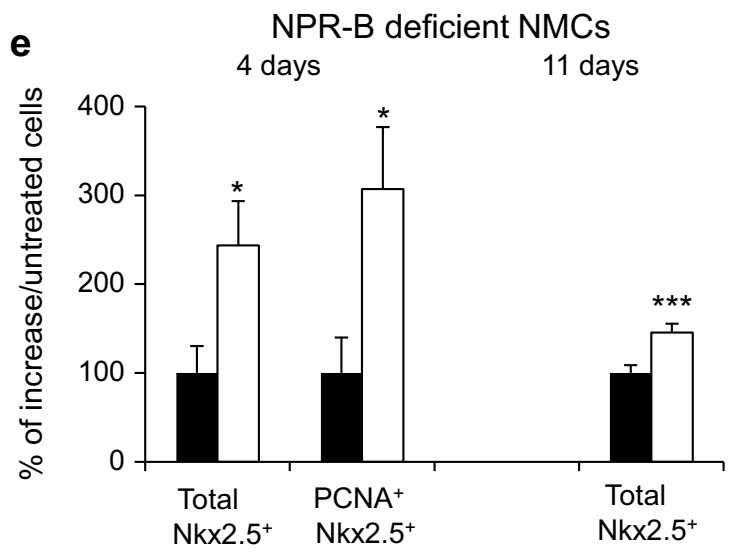

due either from differentiation of CPCs into cardiomyocytes or from proliferation or de-differentiation of mature cardiomyocytes [46]. This latter possibility is, in our study, not supported by the mRNA levels coding for Nkx2.5, c-kit, Troponin $\mathrm{T}$, and $\alpha \mathrm{MHC}$, which did not 
4Fig. 4 BNP stimulates via NPR-A cardiac progenitor cell proliferation in vitro. a. Representative immunostainings of NMCs cultured 4 days in proliferation medium (medium $\mathrm{P}$ ) in the presence (BNP treated) or absence of BNP (untreated) and stained with antibodies against proliferating cell nuclear antigen (PCNA) in green, $\mathrm{Nkx} 2.5$ in red and DAPI in blue. White arrows represent proliferating CPCs (i.e. $\mathrm{PCNA}^{+} \mathrm{Nkx}^{2.5^{+}}$cells). b, d, e The numbers of cells positive for Nkx2.5 and positive for Nkx2.5 and PCNA were counted after 4 and 11 days of culture and related to the total number of nuclei. The numbers of positive cells were counted on at least six different pictures per cell culture, $n=4$ different cell cultures at least. These experiments were performed with wild-type cells (b), or cells deficient for the NPR-A receptor (NPR-A KO cells d) or deficient for the expression of NPR-B (NPR-B deficient cells e) The results of BNP-treated cells were related to those of untreated cells (100\%). c Quantitative relative expression of mRNAs coding for Nkx2.5 in untreated and BNP-treated cells after 4, 7 and 11 days of culture in proliferation medium. $n=7$ different experiments at least. Results expressed as fold increase above the levels in untreated cells. All data are mean $\pm \mathrm{SEM}, * p<0.05 ; * * p<0.01, * * * p<0.005$

differ between hearts of treated and untreated mice (data not shown).

To further investigate an hypothetical effect of BNP treatment on cardiomyocyte proliferation as already described in vitro [5], BrdU was added in the drinking water of the adult mice, 9 days before sacrifice to assess for cardiomyocyte proliferation. The number of cardiomyocyte positive for the BrdU staining was extremely low and no difference can be detected between mice injected with saline or BNP: saline injected: $0.0008 \%$ of the cardiomyocytes proliferated; BNP injected: $0.0013 \%$ (data not shown).

Finally, the possibility that BNP stimulates the differentiation of CPCs into $\mathrm{Nkx} 2.5^{+}$cardiomyocytes in adult hearts was evaluated. Cell lineage tracing experiments were performed using heterozygous Myh6 MerCreMer/TomatoEGFP mice. These mice expressed the Green fluorescent protein (GFP) only in Myh6 positive cells (i.e. mature cardiomyocytes) after the activation of the Cre recombinase with tamoxifen injection (Supplemental Fig. 5A). Heterozygous mice without tamoxifen injection expressed the Tomato protein in all cells (Supplemental Fig. 5A, +peanut oil). As previously shown by others [30], 2 weeks after tamoxifen injection, the large majority of the cardiomyocytes expressed the GFP alone. However, because of the perdurance of the Tomato protein, some cardiomyocytes co-expressed the GFP and Tomato proteins (yellow cells, Supplemental Fig. 5A, +tamoxifen). Fusion events have also been evoked by the group of Molkentin [44]. It is to note that the NMCs involving the CPCs, expressed the Tomato protein even after tamoxifen injection.

2 weeks after a single dose of tamoxifen injection (to prevent cardiac fibrosis induced by several injections of tamoxifen [24]), heterozygous Myh6 MerCreMer/TomatoEGFP mice were injected with $\mathrm{BNP}$ or $\mathrm{NaCl}$ for 2 weeks.
Immunostainings using antibody against $\alpha$-actinin, a cardiomyocyte specific marker, were performed (Supplemental Fig. 5B). In NaCl-injected mice, the cardiomyocytes $\left(\alpha\right.$-actinin $\left.{ }^{+}\right)$expressed the GFP protein alone or with the Tomato protein (Supplemental Fig. 5B), rare $\alpha$-actinin ${ }^{+}$cells expressed the Tomato protein alone. In BNP-treated mice, numerous cardiomyocytes $(\alpha-$ actinin $^{+}$) expressed the Tomato protein without the expression of GFP (white arrows), supporting the fact that the newly formed cardiomyocytes observed in increased number after BNP treatment could originate from the differentiation of CPCs. Quantification of the newly formed cardiomyocytes was performed 2 weeks after the last injection (Supplemental Fig. 5C). Among cardiomyocytes, in saline-injected mice, $0.16 \%$ of cardiomyocytes expressed Tomato protein but not GFP protein. For the same conditions in BNP-treated mice, $3 \%$ of cardiomyocytes were GFP negative and Tomato positive, demonstrating that BNP clearly stimulates cardiomyocyte differentiation in adult mice $(p=0.001)$.

BNP stimulates CPC differentiation

into cardiomyocytes via NPR-B in vitro

To precise the role of BNP in the process of CPC differentiation into mature cardiomyocytes, we cultured neonatal NMCs after expansion with or without BNP in medium C favouring CPC differentiation into cardiomyocytes (Fig. 6). In the presence of BNP, differentiation into cardiomyocytes occurred, as assessed by the increased expressions of mRNAs coding for Nkx2.5, Mlc-2v, $\beta$ and $\alpha$ MHC (Fig. 6a) compared to the levels detected in untreated cells. The presence of mature differentiated cardiomyocytes was also illustrated by immunostaining against Troponin I (Fig. 6d). Troponin I positive cells represented $7 \pm 0.8 \%$ of the NMCs $(n=3$ different experiments) 7 days after the onset of BNP treatment.

To determine which receptor is involved, NMCs isolated from neonatal hearts of NPR-A or NPR-B deficient mice were treated with BNP (Fig. 6b, c). The effects of BNP on wild type and NPR-A KO cells did not differ substantially (Fig. 6b). Some cardiomyocyte differentiation occurred in the NPR-B deficient cells (Fig. 6c), however, this effect of BNP was far lower than in either NPR-A KO or wild-type cells (Fig. 6e).

BNP treatment increases the number of $\mathrm{Nkx} 2.5^{+}$cells in the infarction zone of infarcted hearts

In anticipation that BNP might be used as a therapeutic agent, we injected BNP into mice undergoing myocardial infarction. Myocardial infarction was induced or a sham operation carried out in 10-week-old C57 BL/6 mice. Mice 


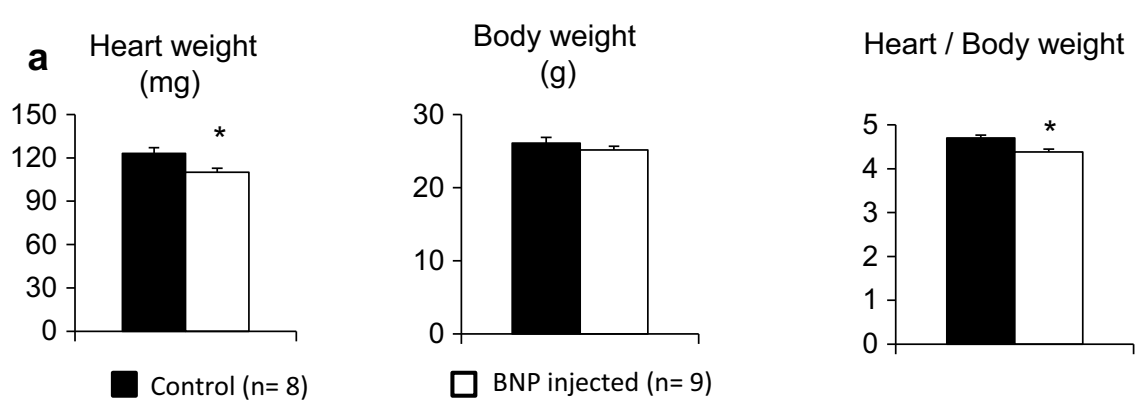

b

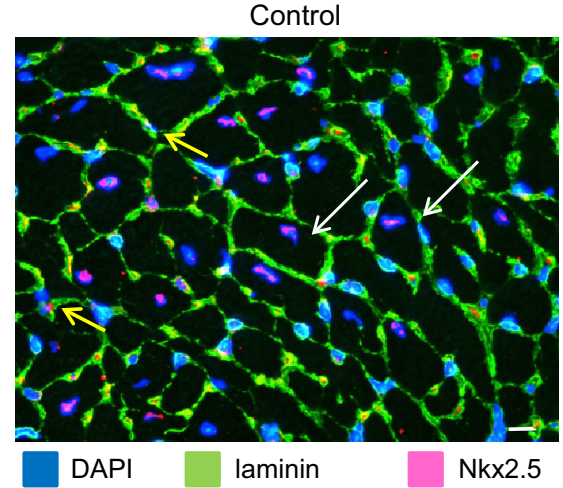

BNP injected
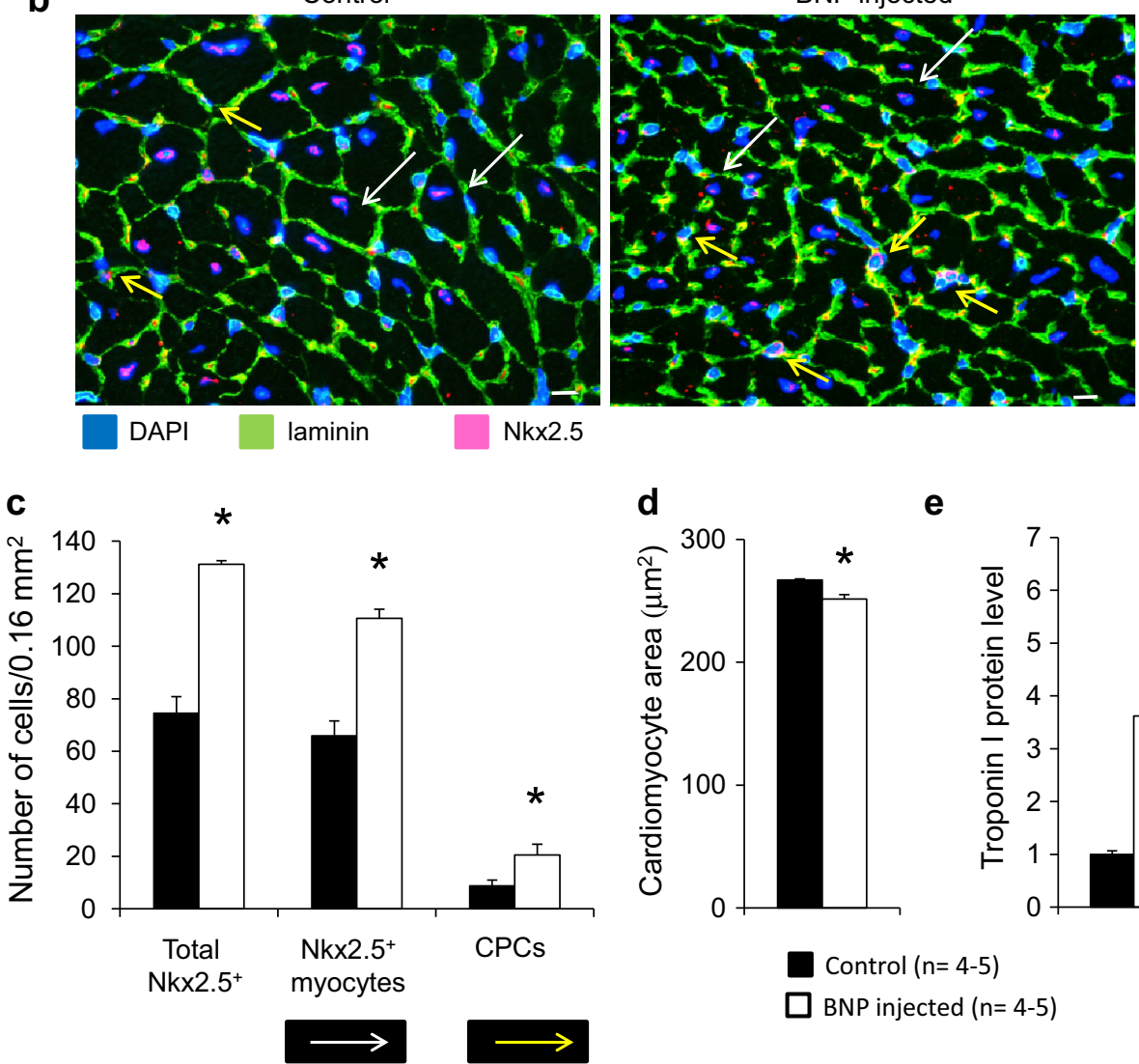

Fig. 5 Treatment of adult mice with BNP leads to higher numbers of newly formed cardiomyocytes and CPCs in the heart compared to saline-injected mice. a Heart weight, body weight and the heart/body weight ratio are shown in control and BNP-injected mice. $n=8$ mice in control group and $n=9$ mice in BNP-injected group. b Representative pictures of hearts from control or BNP-injected mice stained for laminin (green), the nuclear transcription factor $\mathrm{Nkx} 2.5$ (pink) and DAPI (blue). Scale bars represent $10 \mu \mathrm{m}$. White arrows: large cells expressing Nkx2.5: newly formed cardiomyocytes. Yellow arrows: small cells expressing Nkx2.5: CPCs. c Total number of Nkx2.5 cells, number of newly formed cardiomyocytes and of CPCs were counted on heart sections originating from control or BNP-injected mice. Data were obtained from at least six different pictures per

were then treated for 10 days with injections of BNP or saline.

Cardiac function and structures evaluated by echocardiography 1 and 4 weeks after surgery to assess for the d

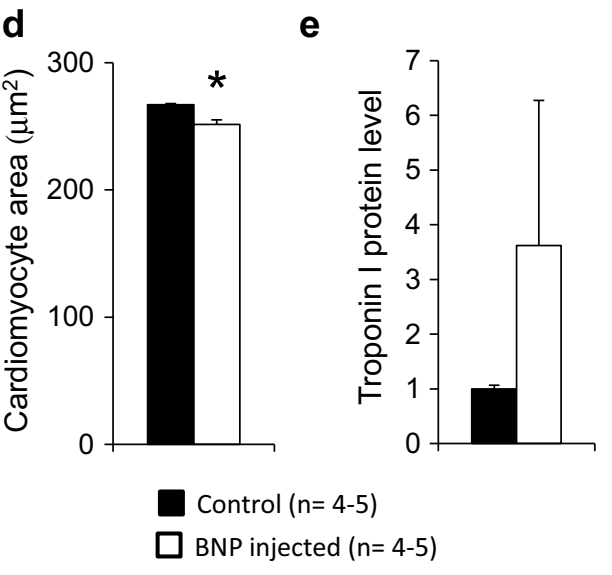

mouse, $n=4$ mice per group. Each picture covered an area of $0.16 \mathrm{~mm}^{2}$. Results expressed as fold increase above the numbers in control hearts. $\mathbf{d}$ The area of cardiomyocytes (without discriminating between $\mathrm{Nkx} 2.5^{+}$or $\mathrm{Nkx} 2.5^{-}$cardiomyocytes) was measured in the hearts of control or BNP-injected mice. Data were obtained from at least 5-6 different pictures per mouse, $n=4$ mice in the control group and $n=5$ mice in the BNP-injected group. Each picture covered an area of $0.16 \mathrm{~mm}^{2} .1183$ cardiomyocytes for the control mice and 1198 cardiomyocytes for the BNP-injected mice were measured. e Quantification of Troponin I protein expression in hearts from control or BNP-injected mice obtained by western blot analysis. For all results, data are mean $\pm \mathrm{SEM},{ }^{*} p<0.05$

protective role of BNP after myocardial infarction (Fig. 7). After 1 week of treatment, no statistically significant effect of BNP was detected in heart structure or function. For this reason, we carried out an additional experiment where 

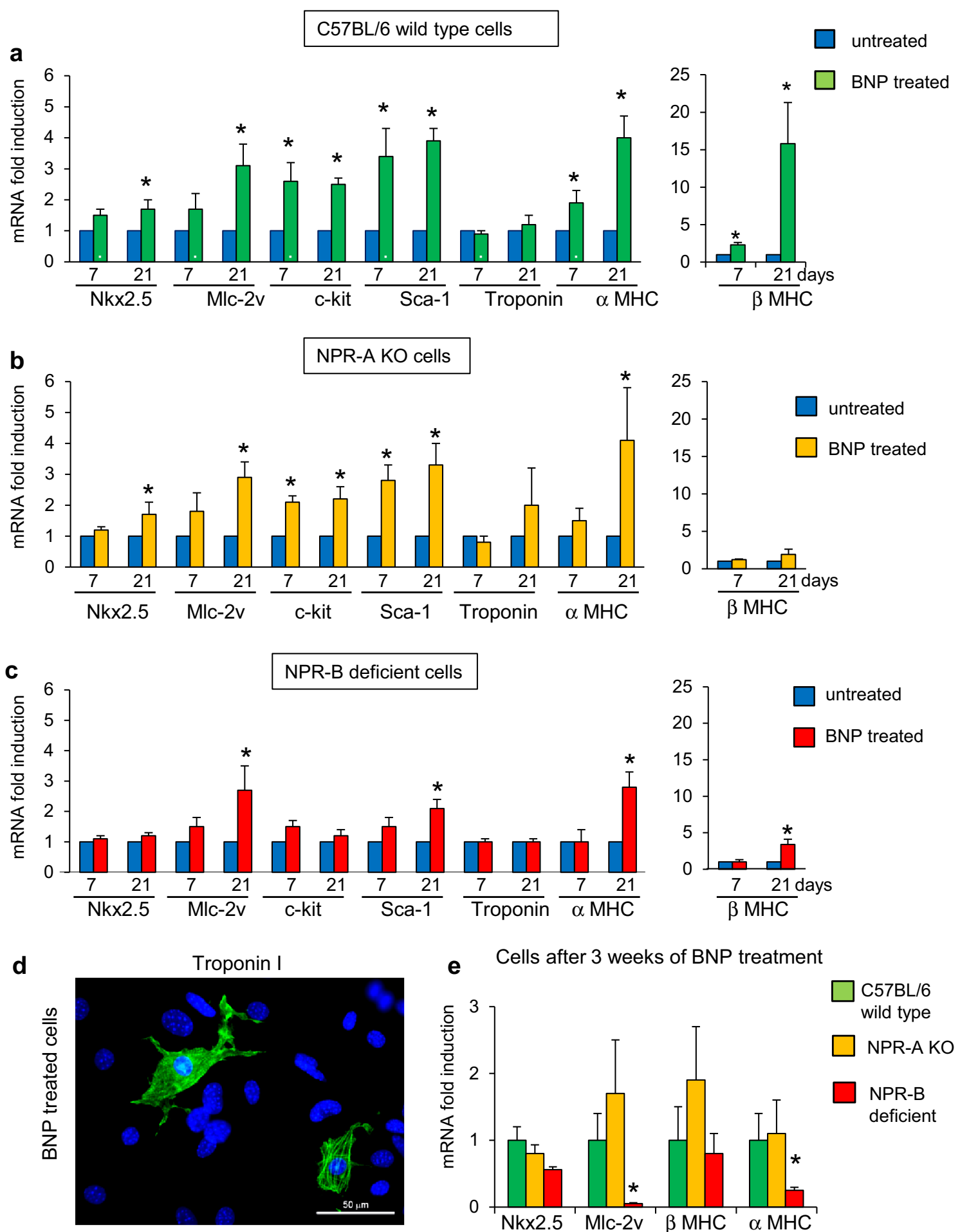

Fig. 6 BNP induces CPC differentiation into cardiomyocytes in vitro via the NPR-B but not the NPR-A receptor. a-c Quantitative relative expression of mRNAs coding for CPC and cardiomyocyte specific genes in wild-type cells and cells deficient for the NPR-A receptor (b) or NPR-B receptor (c) and cultured for 7 or 21 days with (green, yellow or red bars) or without (blue bars) BNP. Results expressed as fold increase above the levels in cells cultured without BNP (untreated cells). $n=10$ different experiments for wild-type cells, $n=6$ different experiments per groups for NPR-A KO cells and $n=9$ different experiments per groups for NPR-B deficient cells. d Wild-type NMCs cultured 21 days with BNP and stained with Troponin I (green) and DAPI (blue). e Comparison by quantitative RT-PCR of mRNAs coding for Nkx2.5, Mlc-2v, beta and alpha MHC in wild-type cells, in NPR-A KO (yellow bars) or NPR-B deficient cells (red bars) after 3 weeks of BNP treatment. Results expressed as fold increase above the levels in wild-type cells. $n=5-6$ different experiments per groups. For all results, data are mean \pm SEM, $* p<0.05$ 
mice were subjected to MI, treated or not with BNP for 10 days and kept until 4 weeks postsurgery. At this time, left ventricular volume and left ventricular end diastolic diameter were significantly lower in treated mice (Fig. 7). As the conditions of preload were different between treated and untreated mice, we corrected the EF for the preload conditions: EF@LV Vol;d. Thus, contractility (EF@LV Vol;d) was twofold increased 4 weeks after MI in BNPtreated groups.

Heart rate and cardiac output did not change 1 and 4 weeks after infarction in BNP treated or saline-injected mice. These results added to the results in unmanipulated adult mice (see paragraph 3.4 and Supplemental Table 2) which showed that BNP at the dose used in this study did not modulate blood pressure, suggest that most BNP effect after MI depends on cardiac rather than on vascular effects. Furthermore, if we consider the percentage of changes of the left ventricle volume as an index of remodeling [22], BNP clearly protected, even after 1 week, the hearts from remodeling (Fig. 7, remodeling index). Taken together, these results indicate that BNP treatment has a cardioprotective effect which develops in a time-dependent manner, consistent with previous observations in a similar model of $\mathrm{MI}$ in rats [32].

BNP treatment prevented the increase of heart weight to body weight ratio induced by infarction (Fig. 8a). At the cellular level, in the infarcted zone, the number of $\mathrm{Nkx} 2.5^{+}$ cells was increased after BNP treatment $(+39 \%, n=5-6$ hearts per group, $p=0.03$ ) (Fig. 8c, d), reflecting higher numbers of CPCs, but also higher number of myocytes as shown by the increased mRNA levels of genes coding for Nkx2.5, Gata-4, Mlc-2v, Troponin T and $\alpha$ MHC (Fig. 8b). In the non-infarcted zone, BNP treatment increased the number of CPCs $(+106 \%, p=0.07)$ and newly formed cardiomyocytes $(+56 \%, p=0.02)$.

The origin of the $\mathrm{Nkx} 2.5^{+}$cells in the infarcted zone was investigated, i.e. of endogenous $\left(\mathrm{CD} 45^{-}\right)$or from the blood or bone marrow origin $\left(\mathrm{CD} 45^{+}\right)$. Interestingly, more $\mathrm{CD} 45^{+}$ $\mathrm{Nkx} 2.5^{+}$cells were detected in BNP treated than in salineinjected infarcted hearts (Supplemental Fig. 6). Thus, in infarcted tissue, progenitor cells both positive and negative for CD45 were found indicative of mixed origin, both extra cardiac and resident. The resident cells may either have survived within the ischemic zone or have infiltrated it from
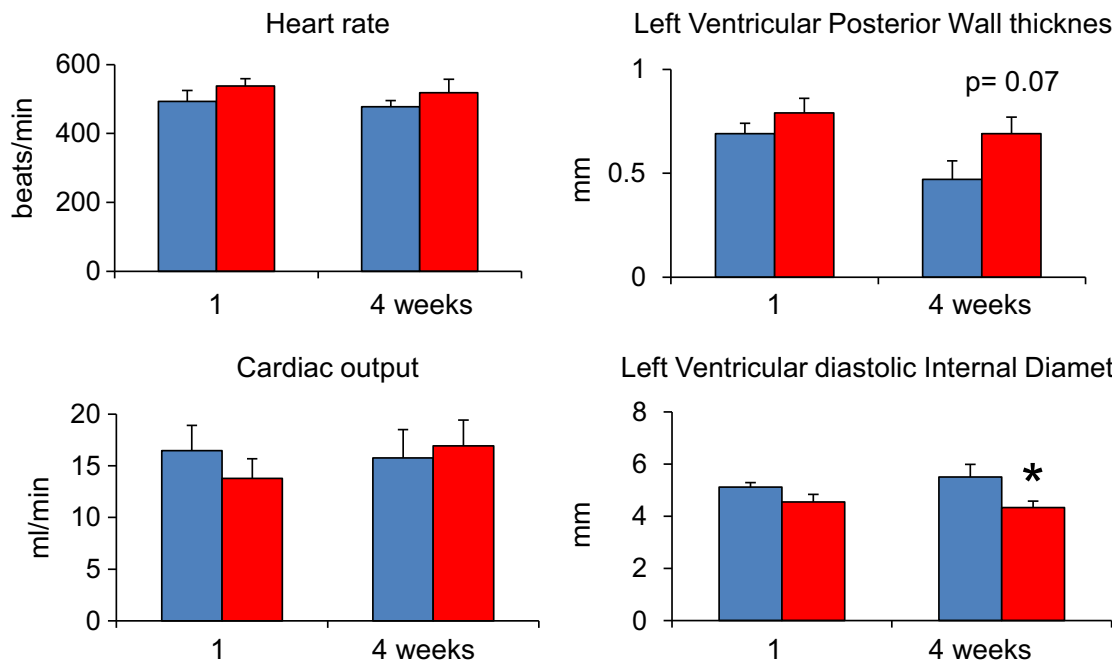

Left Ventricular diastolic Internal Diameter

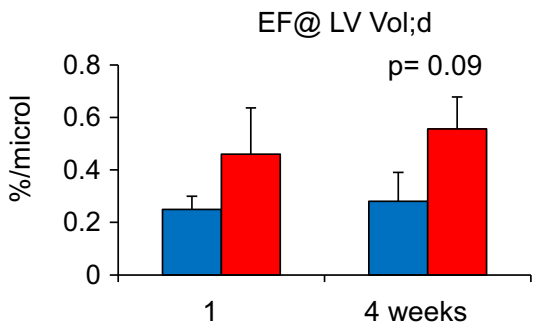

Left Ventricular end-diastolic volume (LV Vol;d)
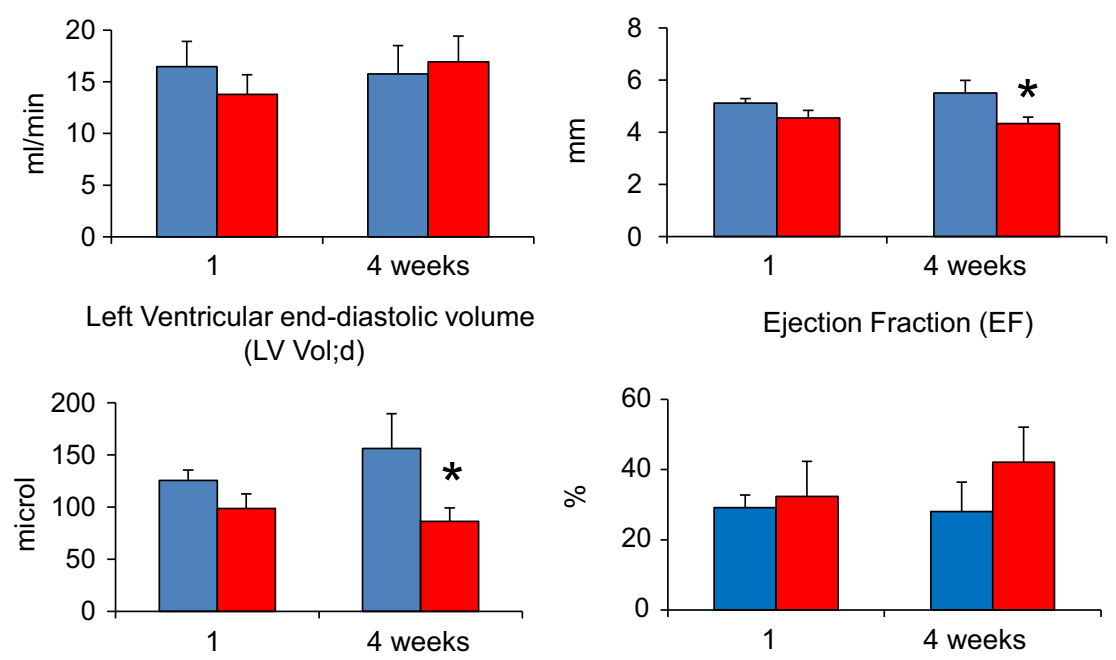

Ejection Fraction (EF)
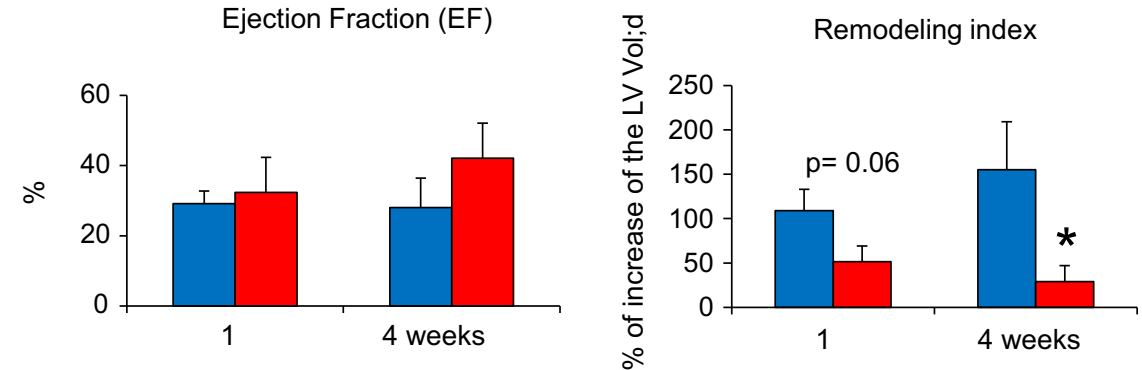

Fig. 7 Cardiac structures and function were measured by echocardiography 1 and 4 weeks after myocardial infarction. Echocardiographic parameters were measured 1 and 4 weeks after myocardial

infarction in saline (MI; $n=61$ week after MI, and $n=74$ weeks after MI) or BNP-treated mice (MI + BNP; $n=71$ week after MI and $n=64$ weeks after MI). ${ }^{*} p<0.05$ 
a

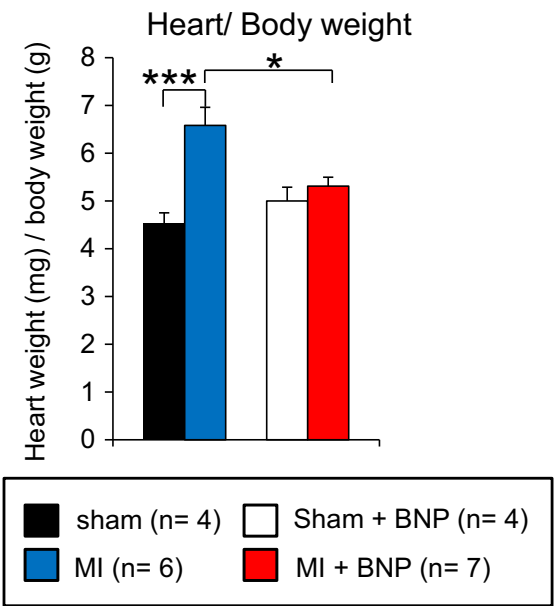

C

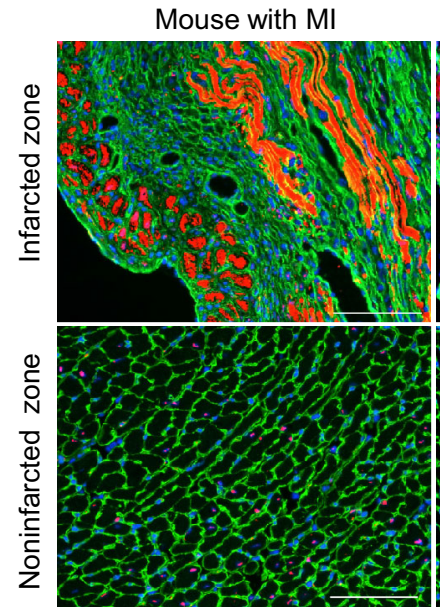

d

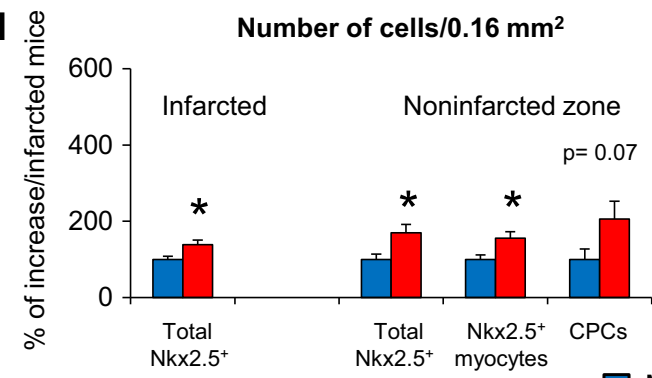

b Infarcted zone

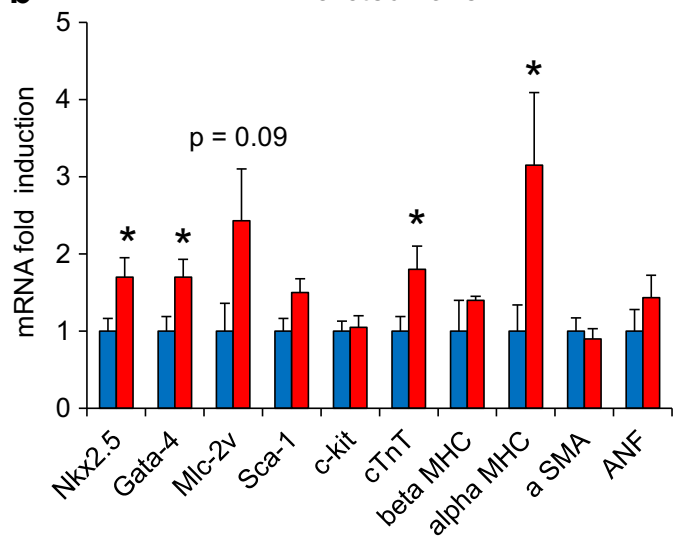

Mouse with $\mathrm{Ml}+\mathrm{BNP}$
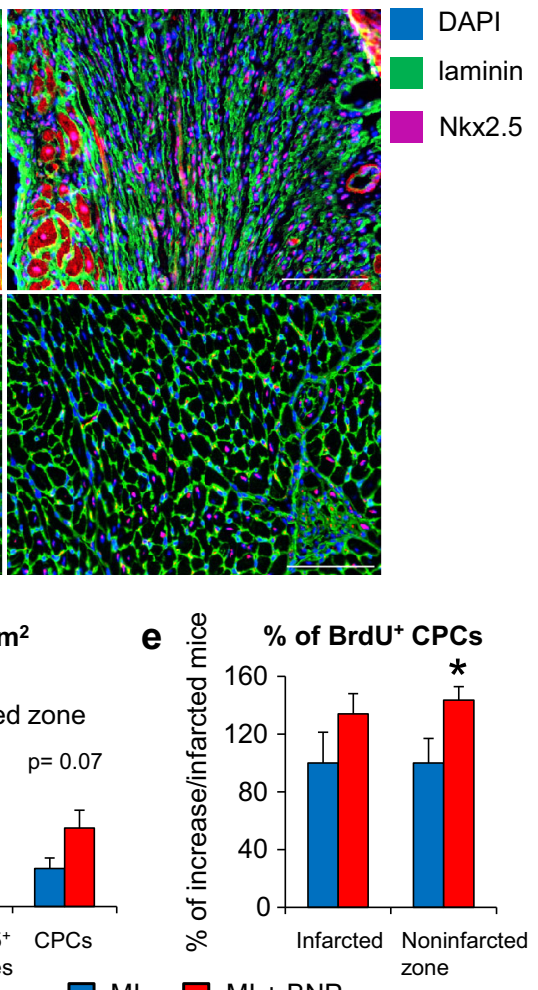

$\mathrm{MI}$
Fig. 8 Increased number of $\mathrm{Nkx} 2.5^{+}$cells in the infarcted and noninfarcted zone of BNP-treated infarcted hearts. a Heart weight to body weight ratio in sham and infarcted mice (MI) treated or not with BNP. b Quantitative relative expression of mRNAs coding for CPC and cardiomyocyte specific genes in the infarction zone in saline (blue bars) and BNP-treated (red bars) mice. $n=6-7$ mice per group. Results expressed as fold increase above the levels in the infarction zone of saline mice. c Representative pictures of the infarcted and non-infarcted zones of infarcted hearts from $\mathrm{NaCl}$ treated (MI) or BNP-treated mice (MI + BNP) stained for DAPI (blue), laminin (green) and the nuclear transcription factor Nkx2.5 (pink). Scale bars $100 \mu \mathrm{m}$. d Total number of $\mathrm{Nkx} 2.5^{+}$cells, $\mathrm{Nkx} 2.5^{+}$cardiomyocytes

neighbouring niches. This latter hypothesis was supported by the fact that a migration gradient of $\mathrm{Nkx} 2.5^{+}$cells was detected as shown in Fig. 8c (infarcted zone). and CPCs, counted on heart sections from infarcted $\mathrm{NaCl}$ or BNPinjected mice. Data obtained from at least six different pictures per mouse, $n=5-6$ mice per group. Each picture covered an area of $0.16 \mathrm{~mm}^{2}$. Results expressed as fold increase above the numbers in the same area in untreated infarcted hearts. e Percentages of $\mathrm{BrdU}^{+}$ CPCs in the infarcted and non-infarcted zone of infarcted hearts with or without BNP treatment. The number of $\mathrm{BrdU}^{+} \mathrm{CPCs}$ was related to the number of nuclei. Data obtained from at least six different pictures per mouse, $n=5-6$ mice per group. Each picture covered an area of $0.16 \mathrm{~mm}^{2}$. Results expressed as fold increase above the numbers in the same area in untreated infarcted hearts. All data are mean $\pm \mathrm{SEM}$, $* p<0.05 ; * * * p<0.005$

In non-infarcted tissue of infarcted hearts immunostainings revealed very few or no cells comitantly positive for Nkx2.5 and CD45 (Supplemental Fig. 6). 
BNP stimulates CPC proliferation in the non-infarcted but not in the infarcted zone of infarcted hearts

Ten days after infarct induction, higher number of $\mathrm{Nkx} 2.5^{+}$ CPCs was detected in the infarcted and non-infarcted area of infarcted hearts treated with BNP (Fig. 8d). The impact of BNP treatment on CPC proliferation was tested by adding BrdU to drinking water $48 \mathrm{~h}$ before sacrifice. At sacrifice, the $\mathrm{BrdU}^{+} \mathrm{CPC}$ were counted. As shown in Fig. 8e, a statistically significant increase in proliferation of CPCs was detected in the non-infarcted, but not in the infarcted zone: $69 \pm 4.6 \%$ of the CPCs proliferated in the non-infarcted area of BNP-treated hearts in comparison to $48 \pm 8 \%$ of CPCs in untreated infarcted hearts $(p=0.04$, Fig. 8e). Few cardiomyocytes (less than 1 cell per $0.16 \mathrm{~mm}^{2}$ of the section) proliferated in the non-infarcted zone of the infarcted hearts and no difference was apparent between hearts of BNP treated and untreated mice (Supplemental Fig. 7).

\section{Discussion}

In the present study, we highlighted a new function for BNP in the heart. Our major new finding is that BNP can modulate cardiac progenitor cell proliferation and differentiation in vivo and in vitro in neonatal and adult hearts. These results are (1) of high interest for understanding the role of BNP in the heart and (2) of great relevance to regenerative therapy of heart diseases, since we identify an agent able to stimulate the proliferation of cardiac progenitor cells in vitro, but also in vivo.

The first clue for an involvement of BNP in CPC proliferation and differentiation into cardiomyocytes comes from our data indicating age-modulation of BNP expression in the heart (Supplemental Fig. 1). This result is consistent with the fact that in humans, BNP concentration in blood is high at birth and then progressively declines, until the age of 10, to levels found in adults [9, 15, 39]. Furthermore, it has been reported that, during embryogenesis, peaks of myocardial BNP concentrations correlate with the different steps of heart formation [8]. Recently, the implication of the natriuretic peptide receptors has been demonstrated in the proliferation of cardiomyocytes during embryogenesis in zebrafish [5]. All these results suggest that BNP could play a role during physiological growth of the heart, both before and after birth.

Further indications for a role of BNP in cardiac growth and/or regeneration come from our finding that CPCs identified in vivo, in neonatal and adult hearts, express the BNP receptors, NPR-A and/or NPR-B (Fig. 1). Although $\mathrm{BNP}$ can share these receptors with other members of the natriuretic peptide family (NPR-A can also bind the atrial natriuretic peptide and NPR-B the C-type related natriuretic peptide) [33], these data strongly support that CPCs are able to respond to BNP. Interestingly, the expression of these receptors is also modulated by ageing, with the levels of NPR-A and NPR-B being higher in neonatal hearts compared to adult hearts (Supplemental Fig. 1).

These results are in accordance with those of other groups demonstrating that BNP could influence the fate of immature precursor cells, such as mouse embryonic stem cells and human or murine endothelial precursor cells (EPCs). In adults, high circulating levels of BNP correlate with high numbers of EPCs in peripheral blood, whereas in mice, BNP treatment leads to a significant increase in bone marrow EPCs expressing Sca-1 and Flk-1 [41]. Interestingly, the angiogenic process in ischemic hind limb of NPR-A KO mice was altered, suggesting that angiogenesis is initiated via NPR-A [6, 23]. Thus, Kuhn et al. showed that BNP was secreted only by activated, and not quiescent, satellite cells in the ischemic hind limb. Secreted BNP acts on EPCs, localised near the satellite cells, to induce their differentiation into blood vessels.

The major new finding of our study is that BNP is able to modulate "endogenous" (i.e. CD45 ${ }^{-}$) precursor cell proliferation and differentiation into cardiomyocytes in hearts during physiological growth and under pathophysiological conditions.

In the BNP-treated hearts, increased number of CPCs resulted from the stimulation of their proliferation as shown by the BrdU experiments in vivo in neonatal and adult infarcted hearts (non-infarcted area) (Figs. 3, 8e) and in the in vitro studies (Fig. 4). In pathological conditions (i.e. after infarction in this study), BNP treatment did not stimulate the CPC proliferation in the infarcted zone but seems to modulate the fate of the "exogenous" (i.e. $\mathrm{CD} 45^{+}$) infiltrating cells. More $\mathrm{Nkx} 2.5^{+} \mathrm{CD} 45^{+}$cells were detected in the infarcted area of BNP-treated hearts when compared to the same zone of untreated mice. This finding thus provides in vivo evidences that infiltrating bone marrow cells in a damaged heart are able to acquire a CPC phenotype as described in vitro [4, 16]. Higher number of $\mathrm{Nkx} 2.5^{+} \mathrm{CD}^{+} 5^{+}$cells in BNP-treated hearts originated either from increased mobilisation and migration of the $\mathrm{CD} 45^{+}$cells from the bone marrow to the heart as already demonstrated [41], or from increased differentiation of these bone marrow cells into CPCs (i.e. $\mathrm{Nkx} 2.5^{+} \mathrm{CD} 45^{+}$ cells).

Increased number of $\mathrm{Nkx} 2.5^{+}$cardiomyocytes was also detected by immunohistology but also by western blot and cell counting (Figs. 2a, c, 5e) in BNP-treated neonatal and adult hearts. The origin of this higher number of $\mathrm{Nkx} 2.5^{+}$ cardiomyocytes in the BNP-treated hearts is under debate. In healthy and infarcted adult hearts, cardiomyocytes expressing the nuclear transcription factor $\mathrm{Nkx} 2.5$ can be 
considered as newly formed cardiomyocytes originating either from CPC differentiation or from the proliferation of the mature cardiomyocytes, or dedifferentiating cardiomyocytes [46]. This latter possibility was not supported in our work (see the results paragraph 3.5).

The majority of our results suggest that BNP is able to stimulate the differentiation of CPCs into mature cardiomyocytes. Indeed, mature cardiomyocytes appeared in the NMC BNP-treated culture in vitro (Fig. 6). In vivo, more cardiomyocytes expressing only the tomato protein and not the GFP protein (i.e. thus originating from CPCs) were detected in MerCreMer/Tomato BNP-treated mice when compared to the same mice injected with saline (Supplemental Fig. 5).

Finally, in our conditions, we detected rare proliferating cardiomyocyte after BNP treatment in adult healthy or infarcted hearts (Supplemental Fig. 7). Recently Becker et al. [5] demonstrated in vitro that the atrial natriuretic peptide (ANF) was able to induce the proliferation of neonatal murine cardiomyocytes in a concentrationdependent manner. Thus, high doses of ANF (higher than $500 \mathrm{nM}$ ) had no effect on cardiomyocyte proliferation. The concentration of BNP used in this study is around $200 \mathrm{nM}$ in adult mice. Thus, we cannot exclude that lower doses of BNP in vivo, could stimulate the proliferation of the cardiomyocytes in the treated mice.

If, as our results indicate, the pathway activated by BNP is important to the function of CPCs and could be a target to induce myocardial regeneration, it is essential to identify its receptor. In our study, we observed clearly that BNP acts via NPR-A to induce CPC proliferation and via NPR$\mathrm{B}$ to induce $\mathrm{CPC}$ differentiation into mature cardiomyocytes in vitro. The fact that both BNP receptors have different role was already described for embryonic stem cells. BNP ligation to the NPR-A is essential to maintain selfrenewal and pluripotency of ES cells, whereas BNP binding to NPR-B will induce their proliferation $[1,2]$. That NPR-B which mediates the effect of BNP on CPC differentiation is of high interest for further therapeutical usage of this peptide. In failing human hearts, an abnormally low density of NPR-A in the myocardium and coronary arteries has been documentated [42] and Dickey et al. demonstrated that NPR-B is the predominant natriuretic peptide receptor in the failing mouse heart after transaortic constriction [17]. An agonist, such as the chimeric natriuretic peptide CD-NP, which already demonstrated cardioprotective effect without inducing hypotension, could thus be an alternative to BNP therapy [27, 35].

BNP has been previously shown to reduce cardiomyocyte apoptosis, fibrosis and to increase angiogenesis in damaged hearts $[10,18,23,45]$. Here in this report, we described a new effect of BNP on CPCs. BNP is able to stimulate CPC proliferation and CPC differentiation into mature cardiomyocytes. This was associated in infarcted hearts with increased cardiac contractility and reduced cardiac remodeling. Thus, BNP or the targeting of its pathway could be useful in cardiac regenerative therapy, either in vitro to foster expansion and priming of isolated precursor cells before their injection to the patient, or in vivo to stimulate the proliferation and differentiation of endogenous CPCs. This new role of BNP is compatible with the new results demonstrating that short BNP treatment or inhibition of the degradation of BNP has cardioprotective effects in patients with heart failure [13, 28]. Thus, in future therapeutic trials of natriuretic peptides or analogues in heart diseases, it would be important to evaluate the impact of treatment on cardiac regeneration [38].

Acknowledgments The authors thank Ms Catherine Pythoud for her helpful work and Mr Alexandre Sarre for his technical expertise. This work is supported by a grant from the Swiss National Science Foundation.(PMPDB-310030-_132491).

Conflict of interest The authors declare that they have no conflict of interest.

Ethical standard All animal studies have been approved by the appropriate ethics committee and have, therefore, been performed in accordance with the ethical standards laid down in the 1964 Declaration of Helsinki and its later amendments. The manuscript does not contain clinical studies or patient data.

\section{References}

1. Abdelalim EM, Tooyama I (2009) BNP signaling is crucial for embryonic stem cell proliferation. PLoS One 4:e5341. doi:10. 1371/journal.pone.0005341

2. Abdelalim EM, Tooyama I (2011) NPR-A regulates self-renewal and pluripotency of embryonic stem cells. Cell Death Dis 2:e127. doi:10.1038/cddis.2011.10

3. Ahmad T, Felker GM (2012) Subcutaneous B-type natriuretic peptide for treatment of heart failure: a dying therapy reborn? J Am Coll Cardiol 60:2313-2315. doi:10.1016/j.jacc.2012.08.991

4. Barile L, Cerisoli F, Frati G, Gaetani R, Chimenti I, Forte E, Cassinelli L, Spinardi L, Altomare C, Kizana E, Giacomello A, Messina E, Ottolenghi S, Magli MC (2011) Bone marrow-derived cells can acquire cardiac stem cells properties in damaged heart. J Cell Mol Med 15:63-71. doi:10.1111/j.1582-4934.2009.00968. $\mathrm{x}$

5. Becker JR, Chatterjee S, Robinson TY, Bennett JS, Panakova D, Galindo CL, Zhong L, Shin JT, Coy SM, Kelly AE, Roden DM, Lim CC, Macrae CA (2014) Differential activation of natriuretic peptide receptors modulates cardiomyocyte proliferation during development. Development 141:335-345. doi:10.1242/dev. 100370

6. Bersell K, Arab S, Haring B, Kuhn B (2009) Neuregulin1/ErbB4 signaling induces cardiomyocyte proliferation and repair of heart injury. Cell 138:257-270. doi:10.1016/j.cell.2009.04.060

7. Burley DS, Baxter GF (2007) B-type natriuretic peptide at early reperfusion limits infarct size in the rat isolated heart. Basic Res Cardiol 102:529-541. doi:10.1007/s00395-007-0672-1

8. Cameron VA, Aitken GD, Ellmers LJ, Kennedy MA, Espiner EA (1996) The sites of gene expression of atrial, brain, and C-type 
natriuretic peptides in mouse fetal development: temporal changes in embryos and placenta. Endocrinology 137:817-824

9. Cameron VA, Ellmers LJ (2003) Minireview: natriuretic peptides during development of the fetal heart and circulation. Endocrinology 144:2191-2194

10. Cataliotti A, Tonne JM, Bellavia D, Martin FL, Oehler EA, Harders GE, Campbell JM, Peng KW, Russell SJ, Malatino LS, Burnett JC Jr, Ikeda Y (2011) Long-term cardiac pro-B-type natriuretic peptide gene delivery prevents the development of hypertensive heart disease in spontaneously hypertensive rats. Circulation 123:1297-1305. doi:10.1161/CIRCULATIONAHA. 110.981720

11. Chen HH (2007) Heart failure: a state of brain natriuretic peptide deficiency or resistance or both! J Am Coll Cardiol 49:1089-1091. doi:10.1016/j.jacc.2006.12.013

12. Chen HH, Glockner JF, Schirger JA, Cataliotti A, Redfield MM, Burnett JC Jr (2012) Novel protein therapeutics for systolic heart failure: chronic subcutaneous B-type natriuretic peptide. J Am Coll Cardiol 60:2305-2312. doi:10.1016/j.jacc.2012.07.056

13. Chen HH, Martin FL, Gibbons RJ, Schirger JA, Wright RS, Schears RM, Redfield MM, Simari RD, Lerman A, Cataliotti A, Burnett JC Jr (2009) Low-dose nesiritide in human anterior myocardial infarction suppresses aldosterone and preserves ventricular function and structure: a proof of concept study. Heart 95:1315-1319. doi:10.1136/hrt.2008.153916

14. D'Souza SP, Baxter GF (2003) B Type natriuretic peptide: a good omen in myocardial ischaemia? Heart 89:707-709

15. Das BB, Raj S, Solinger R (2009) Natriuretic peptides in cardiovascular diseases of fetus, infants and children. Cardiovasc Hematol Agents Med Chem 7:43-51

16. Degeorge BR Jr, Rosenberg M, Eckstein V, Gao E, Herzog N, Katus HA, Koch WJ, Frey N, Most P (2008) BMP-2 and FGF-2 synergistically facilitate adoption of a cardiac phenotype in somatic bone marrow c-kit+/Sca-1+ stem cells. Clin Transl Sci 1:116-125. doi:10.1111/j.1752-8062.2008.00034.X

17. Dickey DM, Flora DR, Bryan PM, Xu X, Chen Y, Potter LR (2007) Differential regulation of membrane guanylyl cyclases in congestive heart failure: natriuretic peptide receptor (NPR)-B, Not NPR$\mathrm{A}$, is the predominant natriuretic peptide receptor in the failing heart. Endocrinology 148:3518-3522. doi:10.1210/en.2007-0081

18. George I, Morrow B, Xu K, Yi GH, Holmes J, Wu EX, Li Z, Protter AA, Oz MC, Wang J (2009) Prolonged effects of B-type natriuretic peptide infusion on cardiac remodeling after sustained myocardial injury. Am J Physiol Heart Circ Physiol 297:H708H717. doi:10.1152/ajpheart.00661.2008

19. Gorbe A, Giricz Z, Szunyog A, Csont T, Burley DS, Baxter GF, Ferdinandy P (2010) Role of cGMP-PKG signaling in the protection of neonatal rat cardiac myocytes subjected to simulated ischemia/reoxygenation. Basic Res Cardiol 105:643-650. doi:10. 1007/s00395-010-0097-0

20. Gottlieb SS, Stebbins A, Voors AA, Hasselblad V, Ezekowitz JA, Califf RM, O'Connor CM, Starling RC, Hernandez AF (2013) Effects of nesiritide and predictors of urine output in acute decompensated heart failure: results from ASCEND-HF (acute study of clinical effectiveness of nesiritide and decompensated heart failure). J Am Coll Cardiol 62:1177-1183. doi:10.1016/j. jacc.2013.04.073

21. Heusch G, Libby P, Gersh B, Yellon D, Bohm M, Lopaschuk G, Opie L (2014) Cardiovascular remodelling in coronary artery disease and heart failure. Lancet 383:1933-1943. doi:10.1016/ S0140-6736(14)60107-0

22. Konstam MA, Kramer DG, Patel AR, Maron MS, Udelson JE (2011) Left ventricular remodeling in heart failure: current concepts in clinical significance and assessment. JACC Cardiovasc Imaging 4:98-108. doi:10.1016/j.jcmg.2010.10.008
23. Kuhn M, Volker K, Schwarz K, Carbajo-Lozoya J, Flogel U, Jacoby C, Stypmann J, van Eickels M, Gambaryan S, Hartmann M, Werner M, Wieland T, Schrader J, Baba HA (2009) The natriuretic peptide/guanylyl cyclase-a system functions as a stress-responsive regulator of angiogenesis in mice. J Clin Invest 119:2019-2030. doi:10.1172/JCI37430

24. Lexow J, Poggioli T, Sarathchandra P, Santini MP, Rosenthal N (2013) Cardiac fibrosis in mice expressing an inducible myocardial-specific Cre driver. Dis Model Mech 6:1470-1476. doi: $10.1242 / \mathrm{dmm} .010470$

25. Li J, Loukili N, Rosenblatt-Velin N, Pacher P, Feihl F, Waeber B, Liaudet L (2013) Peroxynitrite is a key mediator of the cardioprotection afforded by ischemic postconditioning in vivo. PLoS One 8:e70331. doi:10.1371/journal.pone.0070331

26. Lyu T, Zhao Y, Zhang T, Zhou W, Yang F, Ge H, Ding S, Pu J, $\mathrm{He} B$ (2014) Natriuretic peptides as an adjunctive treatment for acute myocardial infarction. Int Heart J 55:8-16

27. Martin FL, Sangaralingham SJ, Huntley BK, McKie PM, Ichiki T, Chen HH, Korinek J, Harders GE, Burnett JC Jr (2012) CDNP: a novel engineered dual guanylyl cyclase activator with antifibrotic actions in the heart. PLoS One 7:e52422. doi:10.1371/ journal.pone.0052422

28. McMurray JJ, Packer M, Desai AS, Gong J, Lefkowitz MP, Rizkala AR, Rouleau JL, Shi VC, Solomon SD, Swedberg K, Zile MR, Investigators P-H, Committees (2014) Angiotensin-neprilysin inhibition versus enalapril in heart failure. N Engl J Med 371:993-1004. doi:10.1056/NEJMoa1409077

29. Moilanen AM, Rysa J, Mustonen E, Serpi R, Aro J, Tokola H, Leskinen H, Manninen A, Levijoki J, Vuolteenaho O, Ruskoaho H (2011) Intramyocardial BNP gene delivery improves cardiac function through distinct context-dependent mechanisms. Circ Heart Fail 4:483-495. doi:10.1161/CIRCHEARTFAILURE.110. 958033

30. Muzumdar MD, Tasic B, Miyamichi K, Li L, Luo L (2007) A global double-fluorescent Cre reporter mouse. Genesis 45:593-605. doi:10.1002/dvg.20335

31. O'Connor CM, Starling RC, Hernandez AF, Armstrong PW, Dickstein K, Hasselblad V, Heizer GM, Komajda M, Massie BM, McMurray JJ, Nieminen MS, Reist CJ, Rouleau JL, Swedberg K, Adams KF Jr, Anker SD, Atar D, Battler A, Botero R, Bohidar NR, Butler J, Clausell N, Corbalan R, Costanzo MR, Dahlstrom U, Deckelbaum LI, Diaz R, Dunlap ME, Ezekowitz JA, Feldman D, Felker GM, Fonarow GC, Gennevois D, Gottlieb SS, Hill JA, Hollander JE, Howlett JG, Hudson MP, Kociol RD, Krum H, Laucevicius A, Levy WC, Mendez GF, Metra M, Mittal S, Oh BH, Pereira NL, Ponikowski P, Tang WH, Tanomsup S, Teerlink JR, Triposkiadis F, Troughton RW, Voors AA, Whellan DJ, Zannad F, Califf RM (2011) Effect of nesiritide in patients with acute decompensated heart failure. N Engl J Med 365:32-43. doi:10.1056/NEJMoa1100171

32. Pan Y, Zhu W, Ma J, Xin P, Han B, He Y, Wang Y, Peng T, Wei $M$ (2011) Therapeutic effects of continuous infusion of brain natriuretic peptides on postmyocardial infarction ventricular remodelling in rats. Arch Cardiovasc Dis 104:17-28. doi:10. 1016/j.acvd.2010.09.006

33. Potter LR, Yoder AR, Flora DR, Antos LK, Dickey DM (2009) Natriuretic peptides: their structures, receptors, physiologic functions and therapeutic applications. Handb Exp Pharmacol 191:341-366. doi:10.1007/978-3-540-68964-5_15

34. Ren B, Shen Y, Shao H, Qian J, Wu H, Jing H (2007) Brain natriuretic peptide limits myocardial infarct size dependent of nitric oxide synthase in rats. Clin Chim Acta 377:83-87. doi:10. 1016/j.cca.2006.08.027

35. Rose RA (2010) CD-NP, a chimeric natriuretic peptide for the treatment of heart failure. Curr Opin Investig Drugs 11:349-356 
36. Rosenblatt-Velin N, Lepore MG, Cartoni C, Beermann F, Pedrazzini T (2005) FGF-2 controls the differentiation of resident cardiac precursors into functional cardiomyocytes. J Clin Invest 115:1724-1733. doi:10.1172/JCI23418

37. Rosenblatt-Velin N, Ogay S, Felley A, Stanford WL, Pedrazzini $\mathrm{T}$ (2012) Cardiac dysfunction and impaired compensatory response to pressure overload in mice deficient in stem cell antigen-1. FASEB J 26:229-239. doi:10.1096/fj.11-189605

38. Sangaralingham SJ, Burnett JC Jr, McKie PM, Schirger JA, Chen $\mathrm{HH}$ (2013) Rationale and design of a randomized, double-blind, placebo-controlled clinical trial to evaluate the efficacy of B-type natriuretic Peptide for the preservation of left ventricular function after anterior myocardial infarction. J Card Fail 19:533-539. doi:10.1016/j.cardfail.2013.06.002

39. Schwachtgen L, Herrmann M, Georg T, Schwarz P, Marx N, Lindinger A (2005) Reference values of NT-proBNP serum concentrations in the umbilical cord blood and in healthy neonates and children. Z Kardiol 94:399-404. doi:10.1007/s00392005-0246-x

40. Scott NJ, Ellmers LJ, Lainchbury JG, Maeda N, Smithies O, Richards AM, Cameron VA (2009) Influence of natriuretic peptide receptor-1 on survival and cardiac hypertrophy during development. Biochim Biophys Acta 1792:1175-1184. doi:10. 1016/j.bbadis.2009.09.009

41. Shmilovich H, Ben-Shoshan J, Tal R, Afek A, Barshack I, Maysel-Auslander S, Harats D, Keren G, George J (2009) B-type natriuretic peptide enhances vasculogenesis by promoting number and functional properties of early endothelial progenitor cells. Tissue Eng Part A 15:2741-2749. doi:10.1089/ten.TEA. 2008.0414

42. Singh G, Kuc RE, Maguire JJ, Fidock M, Davenport AP (2006) Novel snake venom ligand dendroaspis natriuretic peptide is selective for natriuretic peptide receptor-A in human heart: downregulation of natriuretic peptide receptor-A in heart failure. Circ Res 99:183-190. doi:10.1161/01.RES.0000232322.06633.d3

43. Sun Y, Deng T, Lu N, Yan M, Zheng X (2010) B-type natriuretic peptide protects cardiomyocytes at reperfusion via mitochondrial calcium uniporter. Biomed Pharmacother Biomed Pharmacother 64:170-176. doi:10.1016/j.biopha.2009.09.024

44. van Berlo JH, Kanisicak O, Maillet M, Vagnozzi RJ, Karch J, Lin SC, Middleton RC, Marban E, Molkentin JD (2014) c-kit+ cells minimally contribute cardiomyocytes to the heart. Nature 509:337-341. doi:10.1038/nature13309

45. Wu B, Jiang H, Lin R, Cui B, Wen H, Lu Z (2009) Pretreatment with B-type natriuretic peptide protects the heart from ischemiareperfusion injury by inhibiting myocardial apoptosis. Tohoku J Exp Med 219:107-114 (JST.JSTAGE/tjem/219.107 [pii])

46. Zhang Y, Li TS, Lee ST, Wawrowsky KA, Cheng K, Galang G, Malliaras K, Abraham MR, Wang C, Marban E (2010) Dedifferentiation and proliferation of mammalian cardiomyocytes. PLoS One 5:e12559. doi:10.1371/journal.pone.0012559 